\title{
Surface functionalized conducting nanofibers for electrically stimulated neural cell function
}

\author{
Rajiv Borah ${ }^{1, *}$, Ganesh C. Ingavle ${ }^{2}$, Ashok Kumar ${ }^{3, \neq}$, Susan R. Sandeman ${ }^{4}$, Sergey V. \\ Mikhalovsky 5,6
}

\section{AUTHOR ADDRESS:}

${ }^{1}$ Life Sciences Division, Institute of Advanced Study in Science \& Technology, Guwahati, 781035, India

${ }^{2}$ Symbiosis Centre for Stem Cell Research, Symbiosis International (Deemed University), Pune, 412115, India

${ }^{3}$ Materials Research Laboratory, Department of Physics, Tezpur University, Tezpur784028, India

${ }^{4}$ Biomaterials and Medical Devices Research Group, School of Pharmacy and Biomolecular Sciences, Huxley Building, University of Brighton, Brighton BN2 4GJ, UK ${ }^{5}$ ANAMAD Ltd, Sussex Innovation Centre, Science Park Square, Falmer, Brighton BN1 9SB, UK

${ }^{6}$ Chuiko Institute of Surface Chemistry, National Academy of Sciences of Ukraine, 17, General Naumov street, Kyiv, 03164, Ukraine

*Rajiv Borah, Ph.D. (Corresponding author)

Life Sciences Division, Institute of Advanced Study in Science \& Technology,

Guwahati, 781035, India

Fax: +91-361-2273062

E-mail: rajiv.borah@iasst.gov.in

\begin{abstract}
:
Strategies involving the inclusion of cell instructive chemical and topographical cues to smart biomaterials in combination with a suitable physical stimulus may be beneficial to enhance nerve regeneration rates. In this regard, we investigate the surface functionalization of Poly[2-methoxy-5-(2-ethylhexyloxy)-1,4-phenylenevinylene]
\end{abstract}

\footnotetext{
${ }^{\ddagger}$ Deceased April 06, 2020
} 
(MEH-PPV) based electroconductive electrospun nanofibers coupled with externally applied electrical stimulus for accelerated neuronal growth potential. In addition, the voltage-dependent conductive mechanism of the nanofibers was studied in depth to interlink intrinsic conductive properties with electrically stimulated neuronal expression. Surface functionalization was accomplished using 3-aminopropyltriethoxysilane (APTES) and 1,6-Hexanediamine (HDA) as an alternative to costly biomolecule coating (e.g. collagen) for cell adhesion. The nanofibers were uniform, porous, electrically conductive, mechanically strong and stable in physiological conditions. Surface amination boosted biocompatibility, $3 \mathrm{~T} 3$ cell adhesion and spreading, whilst the neuronal model rat PC12 cell line showed better differentiation on surface-functionalized mats compared to non-functionalized mats. When coupled with electrical stimulation (ES), these mats showed comparable or faster neurite formation and elongation than the collagen coated mats with no ES condition. The findings indicate that surface amination in combination with ES may provide an improved strategy to faster nerve regeneration using MEH-PPV based neural scaffold.

Keywords: MEH-PPV; Electrospinning; Surface functionalization; Electrical stimulation; Nerve repair.

\section{Introduction}

Neurological disorders due to nerve injury comprise $6.3 \%$ of the global disease burden, affecting circa one billion people according to the World Health Organisation. ${ }^{1}$ Various ischemic, chemical, mechanical, or thermal factors can induce damage in the nervous system, but the responses of the central and peripheral nervous system to damage is fundamentally different. Peripheral nervous system (PNS) can regrow spontaneously when the gap between damaged neurones is small, otherwise surgical intervention is required. In contrast, central nervous system (CNS) cannot repair spontaneously. No effective clinical treatments available to date for that. ${ }^{2}$ Peripheral nerve injury (PNI) is typically caused by trauma and injury due to vehicle accidents, stabbing, gunshot, and falls, including illnesses such as diabetes, which can damage vital organs of the body, resulting in permanent disability. ${ }^{3}$ It has been estimated that 13-23 per 100,000 persons and $2-5 \%$ of trauma patients are exposed to PNI annually. 4,5

A larger defect in PNS must be repaired by inserting a biological/synthetic graft across the damaged gap. Notwithstanding the progress in understanding the 
pathophysiology of PNIs and regeneration, as well as developments in microsurgical techniques, the success rates of reattachment surgery for PNI are unconvincing in general. Approximately $50 \%$ of patients actually accomplish decent to complete functional recovery. ${ }^{6}$ A report suggests $80-90 \%$ of patients possess permanent sensory or motor deficiency after surgery. ${ }^{7}$ Consequently, successful recovery is rare, misguided or coupled with worsening nerve pain. In addition, physiological and functional changes with age result in progressive neuronal loss and thus the regenerative and restorative capacities of nerve fibers are greatly reduced. ${ }^{8}$ Current clinical treatments for PNI include surgical end-to-end co-aptation, autologous nerve grafts, allografts and nerve conduits. Nonetheless, the current treatment techniques are associated with major drawbacks including sensory impairment, scarring and dysfunction at the recipient site, disparity between the transplant graft and the beneficiary nerve and acute shortage of donor neural tissue for multiple operations. Nerve tissue engineering could offer a substitute of the above strategies, where the most essential aspects are cells, scaffolds, and bio/chemical/physical cues. This has resulted in the exploration various neural scaffolds utilizing range of natural and hybrid polymeric materials, which are focused in matching the structure and chemistry of a functional nerve. None of the above methods were shown to produce completely satisfactory results. It should be noted that patients undergoing instant peripheral nerve repair (PNR) have a long distal target denervation duration provided that human regeneration is close to $1 \mathrm{~mm} /$ day. $^{2}$ Delayed axon replenishment may result in significant necrosis in the denervated tissue. In this context, speeding up the regeneration rate may be more effective for restoration of functionality.

Electrical stimulation (ES) has the potential for increasing axonal growth rate and restoring normal activity. The electrical activity in our body such as neural communication through generation of an action potential at a synapse infers an optimal neural scaffold to be electrically conductive. Giving perspective to this notion, ES has received increasing focus in combination with surgical methods for PNR, which has led to the utilization of electrically conducting polymers (CPs) to build conductive neural scaffolds. Currently, CP based biomaterials provide excellent scaffolding flexibility by perfectly promoting electrical connectivity between different stimulus responsive cells through localized stimulation to the region around the polymer versus externally applied electrical signal with excellent level and period regulation. CP based biomaterials possess remarkable charge injection ability and charge-discharge characteristics which are even better than highly conductive graphene and carbon nanotubes. ${ }^{9}$ They can therefore effectively 
polarize the cell membrane resulting in improved cell adhesion and proliferation as well as axon regrowth. ${ }^{9,10}$ ES triggers ion release and absorption from/by the scaffold, the electrophoretic localization of receptor proteins and the adsorption of cell adhesion molecules like fibronectin on the biomaterial's surface, which ultimately assists faster neurite outgrowth. ${ }^{11}$

CPs can be modified with various biochemical or adhesive cues for intended applications. Furthermore, CPs can be tailor-made to meet required biocompatibility, programmable biodegradability, porosity and aligned 3D matrices, which are mechanically stable enough to imitate the extracellular matrix. Additionally, their physical, chemical and optical properties are also adjustable by exogenous stimuli (e.g. electrical/magnetic signal, light, $\mathrm{pH}$ ) after synthesis. ${ }^{12}$ CPs like polypyrrole (PPy), polyaniline (PAni) and poly(3,4-ethylenedioxythiophene) (PEDOT) were reported for electrically triggered neurite development. Nevertheless, the wide-spread use of CP based biomaterials in nerve repair is limited due to their poor solubility and nonbiodegradability.

2-methoxy-5-(20-ethyl-hexyloxy)-1,4-phenylene vinylene (MEH-PPV) is a less explored CP for tissue scaffold applications though it has greater solubility in a number of organic solvents, viz. chloroform, toluene, and chlorobenzene. ${ }^{13} \mathrm{MEH}-\mathrm{PPV}$ has been explored for biomolecule immobilization owing to its higher density of hole-trap. ${ }^{14}$ Due to its better solubility, it can offer better electrospinnability to construct 3D nanofibrous biomaterial scaffold as compared to other CPs such as PPy, PAni or PEDOT. In our previous reports, we demonstrated previously the fabrication of electrospun nanofibers of MEH-PPV, as a potential neural scaffold. ${ }^{15}$ However, MEH-PPV based electrospun nanofibers without any biomolecule coating such as collagen showed poor cell adhesion and consequently, no or lesser neurite growth. Such surface coating strategies involving costly biomolecules viz., fibronectin, laminin, collagen, RGD peptide etc. are expensive and complex due to multiple conjugation steps. ${ }^{16,17}$ Thus, a convenient and economical way to resolve these limitations is required. 


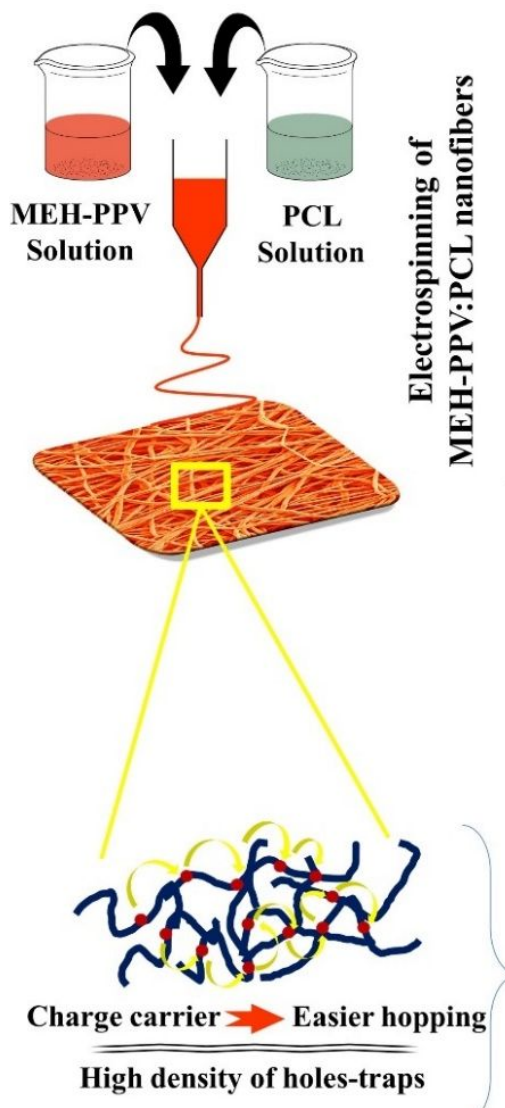

High density of holes-traps
APTES, 80\% Ethanol, RT, 18 h

OR

HDA, Isopropanol, $40^{\circ} \mathrm{C}, 3 \mathrm{~h}$

Surface functionalization
Enhanced fibroblast adhesion and spreading
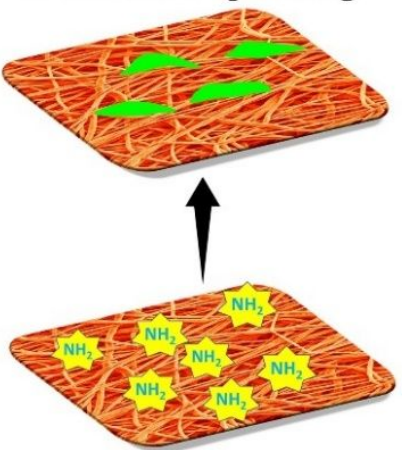

Amine functionality introduced on surface

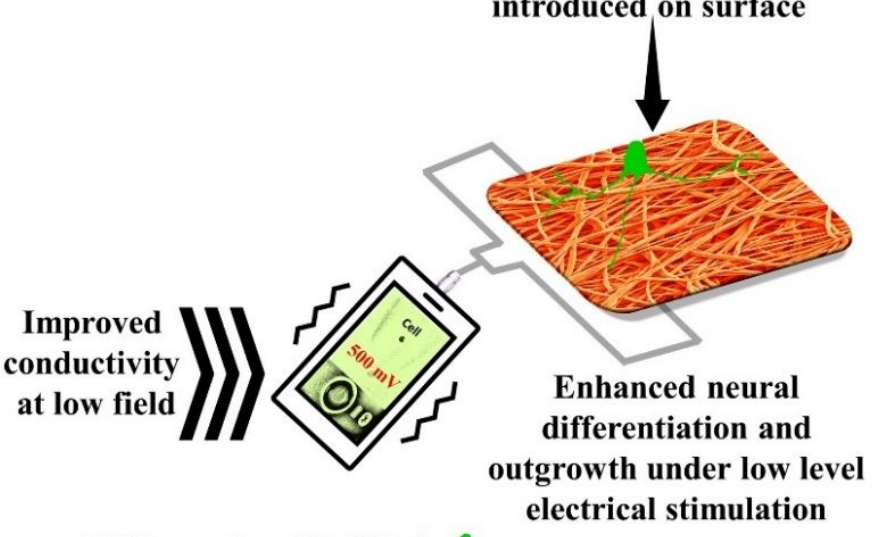

Differentiated PC12

Figure 1. Scheme of work carried out in the present report. Electrospinning of blend of MEH-PPV and PCL to produce nanofibrous scaffold followed surface functionalization to impart amino functional groups to confer bioactivity. Assessment of fibroblast activity on the functionalized nanofibers to confirm the bioactivity followed by low level electrical stimulation of PC12 cells to evaluate their potential as neural scaffold. Intrinsic voltage dependent conductive mechanisms of the nanofibers were interlinked with improved neurite development.

In this regard, functionalization of the biomaterial surface by amino $\left(-\mathrm{NH}_{2}\right)$ groups is an appropriate alternative to obtain a positively charged surface under physiological conditions, and thus, allow a favourable electrostatic interaction between the cell and biomaterial for cell adhesion. ${ }^{18}$ Besides, the amino groups can also interact covalently with tans-membrane proteins via amide bond. ${ }^{19,20}$ This study explored a blend of MEHPPV with polycaprolactone (PCL) electrospun at multiple composition proportions producing different sized nanofibers, followed by surface functionalization using 3aminopropyltriethoxysilane (APTES) and 1,6-Hexanediamine (HDA). APTES and HDA 
have been extensively explored in biomedical research owing to their simple structure and affordability. ${ }^{21-25}$ PCL is an FDA approved for medical use and it was used in the blend to obtain bead free nanofibers, without compromising the electrical conductivity of the resultant nanofibers. This study carried out a detailed analysis of the impact of surface functionalization on physico-chemical, and biological properties of the electrospun nanofibers. The goal of this research was to exploit the cumulative impact of nanofiber structure, surface functionalization and ES on enhancement of neuronal growth characteristics of PC12 cells through these electrospun conductive nanofibers. Moreover, this study for the first time has attempted to interlink the voltage dependent intrinsic conductive properties of an MEH-PPV based biomaterial with the electrically stimulated expression of neuronal characteristics on such biomaterials. The scheme of work undertaken is depicted in Figure 1.

\section{Materials and Methods}

\subsection{Materials}

MEH-PPV (Mol. wt. 150K-250K), PCL (Mol. wt. 80K), iron (III) chloride $\left(\mathrm{FeCl}_{3}\right.$, anhydrous, powder, $\geq 99.99 \%$ ), APTES ( $\geq 98 \%$ ) and HDA ( $\geq 99 \%)$, bought from Sigma, UK, were used for material fabrication. Solvents such as chloroform, dimethylformamide (DMF), and dichloromethane (DCM) were used as received from Sigma, UK. Cell culture reagents used in this work were mentioned in the appropriate method sections. CellTiter 96® AQueous One Solution (Promega, UK) was used for MTS assay.

\subsection{Fabrication of MEH-PPV:PCL nanofibers}

$0.5 \mathrm{wt} \%$ of MEH-PPV was mixed in chloroform:DMF (60:40 v/v) solution, followed by doping with $2 \%(\mathrm{w} / \mathrm{w}) \mathrm{FeCl}_{3}$ as reported previously. ${ }^{15} 14 \mathrm{wt} \%$ of PCL was dissolved in a DCM:DMF solution (60:40 v/v), separately. MEH-PPV and PCL solutions were blended at volume ratios of 20:80, 40:60, 50:50 and 60:40 under constant stirring for $2 \mathrm{~h}$ at 100$150^{\circ} \mathrm{C}$ until a complete dispersion. Electrospinning was performed by a syringe pump (KDS 200, KD Scientific Inc., USA) at a voltage of $18 \mathrm{kV}$ from a power supply (Spellman, UK) and flow rate of $0.5 \mathrm{~mL} / \mathrm{h}$. Nanofibers were accumulated on an aluminum foil wrapped copper plate at $16 \mathrm{~cm}$ away from the needle tip. The as-spun nanofibrous mats were air dried for $12 \mathrm{~h}$ and removed carefully from the aluminum foil. The detailed scheme of electrospinning process including the material processing steps was shown in

\section{Figure S1.}




\subsection{Surface functionalization}

Surface functionalization of the as-electrospun nanofibrous mats was accomplished using APTES and HDA to increase surface hydrophilicity as shown in Figure 1, according to previous protocol. ${ }^{26}$ Briefly, the electrospun mats were incubated in 10\% APTES in ethanol for $18 \mathrm{~h}$ at room temperature followed by washing three times with ethanol and distilled water to eliminate free molecules. For functionalization with HDA, the electrospun mats were treated in $5 \mathrm{wt} \%$ HDA in isopropanol for $3 \mathrm{~h}$ at $40^{\circ} \mathrm{C}$ followed by washing three times to remove unbound molecules.

\subsection{Analytical techniques}

Morphological studies were accomplished with the help of a field emission scanning electron microscope (FESEM, Carl Zeiss SIGMA, Germany). The X-ray diffraction (XRD) patterns of the electrospun mats were analyzed using a D8 FOCUS diffractometer (Bruker AXS, Germany) with $\mathrm{Cu} K_{\alpha}$ radiation $(\lambda=1.5406 \AA)$ in an angular range $10-70^{0}$ in $2 \theta$, in steps of $0.05^{\circ}$. The detailed methodology to calculate the $d$-spacings, domain length $(\mathrm{L})$, and strain $(\varepsilon)$ using these XRD patterns has been described in the Supporting Information.

X-ray photoelectron spectroscopy (XPS) was carried out using an ESCALAB $250 \mathrm{Xi}$ (Thermo Scientific) device fitted with Al Ka X-ray source. Vibration spectroscopy was conducted using a PerkinElmer 2000 spectrophotometer. The mechanical properties of the electrospun mats were tested using a TA.XT plus Texture Analyser (Stable Micro System, UK) fitted with a $2 \mathrm{~kg}$ load. Steady state current-voltage (I-V) measurement of various mats was tested by a Keithley 2450 source meter using two probe technique at a $\mathrm{DC}$ voltage sweep from 0 to $\pm 10 \mathrm{~V}$ at room temperature.

\subsection{Stability test}

The nanofibrous mats were incubated for 45 days in PBS with $\mathrm{pH}=7.4$ in a physiological condition at $37^{\circ} \mathrm{C}$, as described in previous report. ${ }^{26}$ Any change in morphology and conductivity were assessed using SEM and current-voltage (I-V) measurement characteristics to assess the degradation and stability of electrospun mat after 45 days. The mats were washed two times with deionized water to eliminate impurities and dried for analysis. Percentage of mass loss in PBS was calculated using the following formula:

$$
\% \text { Mass loss }=\frac{\text { Difference in mass after incubation in PBS (in mg) }}{\text { Original mass before incubation in PBS (in mg) }} \times 100 \%
$$




\subsection{Cell culture}

The nanofibrous mats were carved into a $5 \mathrm{~mm}$ diameter size for the cytotoxicity assessment and a $10 \mathrm{~mm}$ diameter size for live-dead imaging, immunocytochemistry and cellular adhesion studies. Tissue culture plastic (TCP) used with a $0.01 \%$ collagen, Type I (Sigma, UK) coating for PC12 cell viability assay due to poor cell attachment. Mats were incubated in aseptic PBS for a day followed by UV sterilization for $2 \mathrm{~h}$.

A mouse embryonic 3T3 fibroblast cell line (P15), NIH 3T3 (ATCC@ CRL-1658TM) was employed to examine the surface amination mediated cell-biomaterial interaction. Cells were maintained in Dulbecco's modified Eagle's medium (DMEM) (Sigma, UK) with 10\% fetal bovine serum (FBS) (Sigma, UK) supplement and 1\% penicillinstreptomycin (Sigma, $\mathrm{UK}$ ) at $37^{\circ} \mathrm{C}$ in $5 \% \mathrm{CO}_{2}$. A $0.25 \%$ trypsin-EDTA solution (Sigma, UK) was used every 3 days to conduct cell replication.

A rat pheochromocytoma PC-12 (ATCC ${ }^{\circledR}$ CRL-1721 ${ }^{\mathrm{TM}}$ ) cell line (P3) was used to study the surface amination assisted neuronal differentiation potential of the electrospun mats. Cells were grown in RPMI-1640 (Sigma, UK) media enriched with 10\% horse serum (Sigma, UK), 5\% FBS and 1\% penicillin-streptomycin solution and maintained at $37^{\circ} \mathrm{C}$ in $5 \% \mathrm{CO}_{2}$. Cells were transferred weekly. After 24 hours, the expansion medium was substituted by an RPMI-1640 differentiating medium containing $0.1 \%$ horse serum, $1 \%$ penicillin-streptomycin and $100 \mathrm{ng} / \mathrm{mL}$ NGF for neural differentiation.

\subsection{MTS proliferation assay}

For cytotoxicity studies, 3T3 and PC12 cells were harvested on various mats at concentrations of $5 \times 10^{3}$ and $1 \times 10^{4}$ cells per well, respectively, in 96 well plate. ${ }^{27}$ After $24 \mathrm{~h}$, the cell seeded mats were washed with PBS twice and then, 3-(4,5-dimethylthiazol2-yl)-5-(3-carboxymethoxyphenyl)-2-(4-sulfophenyl)-2H-tetrazolium, inner salt) (MTS) reagent was applied in 1:5 dilution to each well. After incubation for $2 \mathrm{~h}$ at $37^{\circ} \mathrm{C}$, absorbance was recorded at $490 \mathrm{~nm}$ and the \% cell viability was determined as given below:

$$
\% \text { Cell viability }=\frac{\mathrm{Abs}_{\text {sample }}-\mathrm{Abs}_{\text {blank }}}{\mathrm{Abs} \text {-ve control }-\mathrm{Abs}_{\text {blank }}} \times 100 \%
$$

All experiments were repeated four times.

2.8 Live-dead assay 
The viable and dead cells seeded on different electrospun mats were visualized using calcein-AM (stains live), ethidium homodimer (EthD-1, stains dead) and DAPI (stains nucleus) staining of $3 \mathrm{~T} 3$ cells. ${ }^{28} 1 \times 10^{4}$ cells were seeded on per mats and imaging was accomplished at 24, 48 and $72 \mathrm{~h}$ to track the $3 \mathrm{~T} 3$ cell morphology and spreading on the non-functionalized and functionalized mats. After rinsing three times with PBS, the cell laden mats were stained with $4 \mu \mathrm{M}$ EthD-1, $2 \mu \mathrm{M}$ calcein AM and DAPI in PBS followed by incubation for $30 \mathrm{~min}$ at room temperature before imaging.

2.9 Beta (III) tubulin immunocytochemistry

To validate the neuronal differentiation of PC12 cells, immunocytochemistry was carried out with a beta III-tubulin neuronal marker. ${ }^{29} 1 \times 10^{5}$ PC12 cells were seeded on each sample in differentiating medium. After 7 days, the cell laden mats were rinsed with PBS followed by methanol fixation for $5 \mathrm{~min}$, which after three times PBS washing incubated with 1\% BSA (Sigma, UK), 10\% goat serum (Sigma, UK) and $0.3 \mathrm{M}$ glycine (Sigma, UK) in $0.1 \%$ tween PBS (Sigma, UK) for $1 \mathrm{~h}$. Then, the cell laden mats were treated with $5 \mu \mathrm{g} / \mathrm{mL}$ of primary antibody Rb pAb to anti beta III tubulin (ab18207, Abcam, UK) for $6 \mathrm{~h}$ at $40^{\circ} \mathrm{C}$ followed by PBS washing and incubation with $2 \mu \mathrm{g} / \mathrm{mL}$ of secondary antibody Goat pAb to Rb IgG Alexa fluor 488 (ab150077, Abcam, UK) at room temperature for 1h. DAPI was used for counterstaining the nuclei and imaging was carried out with the help of a Confocal Laser Scanning Microscope (Leica Microsystems, UK). As PC12 cells effectively adhere to collagen, one set of the non-functionalized mats was coated with collagen I.

\subsection{Cell adhesion test}

3T3 cell attachment and their morphology on different nanofibrous mats were assessed using SEM analysis after 3 days. 3 T3 cell laden mats were washed with PBS followed by $4 \%$ glutaraldehyde fixation for $30 \mathrm{~min}$ at $40^{\circ} \mathrm{C}$. Similarly, SEM was conducted to assess differentiated morphology of PC12 cells on multiple mats after one week. After PBS wash, PC12 cells were treated with $4 \%$ glutaraldehyde at $4^{\circ} \mathrm{C}$ for $45 \mathrm{~min}$. All cell laden mats were processed serially through dehydration steps using 30\%, 50\%, 60\%, 70\%, 80\%, 90\% and $100 \%$ ethanol for $10 \mathrm{~min}$ each. Air dried mats were used for analysis.

\subsection{Electrical stimulation}

PC12 cells grown on the collagen coated and surface functionalized nanofibrous mats, were electrically stimulated according to our previous report. ${ }^{15,26}$ Briefly, the ES set up 
was made using a 24 well cell culture plate. Each electrospun mat with $15 \mathrm{~mm}$ in diameter was connected to an Ag wire and fixed in the wells of the plate, which acted as the working electrode (WE). Additionally, each mat was fitted with ThinCert ${ }^{\mathrm{TM}}$ cell culture inserts with a working volume of 0.4-1.2 $\mathrm{mL}$ with bottom membrane separated. The insert edges were secured with poly(dimethylsiloxane) (PDMS, SYLGARD ${ }^{\circledR} 184$, Sigma). A Pt (platinum) wire held at $1 \mathrm{~cm}$ away from the mat, was acted as counter electrode (CE). The whole set up as depicted in Figure S9(a) was UV-sterilized for 3 h. $1 \times 10^{3}$ cells were cultured in each well and a potential of $500 \mathrm{mV} / \mathrm{cm}$ was delivered to the cells in the differentiating medium using a portable bipotentiostat (EmStat Blue, PalmSens BV, Netherlands) for $2 \mathrm{~h}$ per day for three continuous days. A double pulsed potential chronoamperometric technique was employed for ES. Cells were maintained for the next $72 \mathrm{~h}$ with no ES. PC12 cells grown under the similar arrangement were regarded as a control for 7 days without ES on all electro spun mats. The differentiating medium was replaced every two days throughout the experiment. Cells were immunostained using beta (III) tubulin neuronal marker and imaged using confocal microscopy as explained in Section 2.9. All experiments were conducted $n=6$.

\subsection{Statistical analysis}

All tests with a minimum of $\mathrm{n}=3$ were replicated. Two-way analysis of variance (ANOVA) analysis was used to evaluate the statistical significance. Statistically significance at $\alpha=0.05$ or 0.01 , as appropriate, were identified.

Table 1: Coding of various versions samples.

\begin{tabular}{|c|c|c|c|c|}
\hline $\begin{array}{c}\text { Composition } \\
\text { ratio } \\
\text { MEH- } \\
\text { PPV:PCL }\end{array}$ & Pristine & $\begin{array}{c}\text { APTES } \\
\text { functionalized } \\
\text { samples }\end{array}$ & $\begin{array}{c}\text { HDA } \\
\text { functionalized } \\
\text { samples }\end{array}$ & $\begin{array}{c}\text { Collagen } \\
\text { coated } \\
\text { samples }\end{array}$ \\
\hline 20:80 & $\mathrm{MP}_{20: 80}$ & AFMP $_{20: 80}$ & HFMP $_{20: 80}$ & $\mathrm{CMP}_{20: 80}$ \\
\hline $40: 60$ & $\mathrm{MP}_{40: 60}$ & $\operatorname{AFMP}_{40: 60}$ & HFMP $_{40: 60}$ & $\mathrm{CMP}_{40: 60}$ \\
\hline $50: 50$ & $\mathrm{MP}_{50: 50}$ & $\mathrm{AFMP}_{50: 50}$ & $\mathrm{HFMP}_{50: 50}$ & $\mathrm{CMP}_{50: 50}$ \\
\hline $60: 40$ & $\mathrm{MP}_{60: 40}$ & $\operatorname{AFMP}_{60: 40}$ & HFMP $_{60: 40}$ & $\mathrm{CMP}_{60: 40}$ \\
\hline
\end{tabular}




\section{Results and Discussions}

\subsection{Structure and morphology studies}
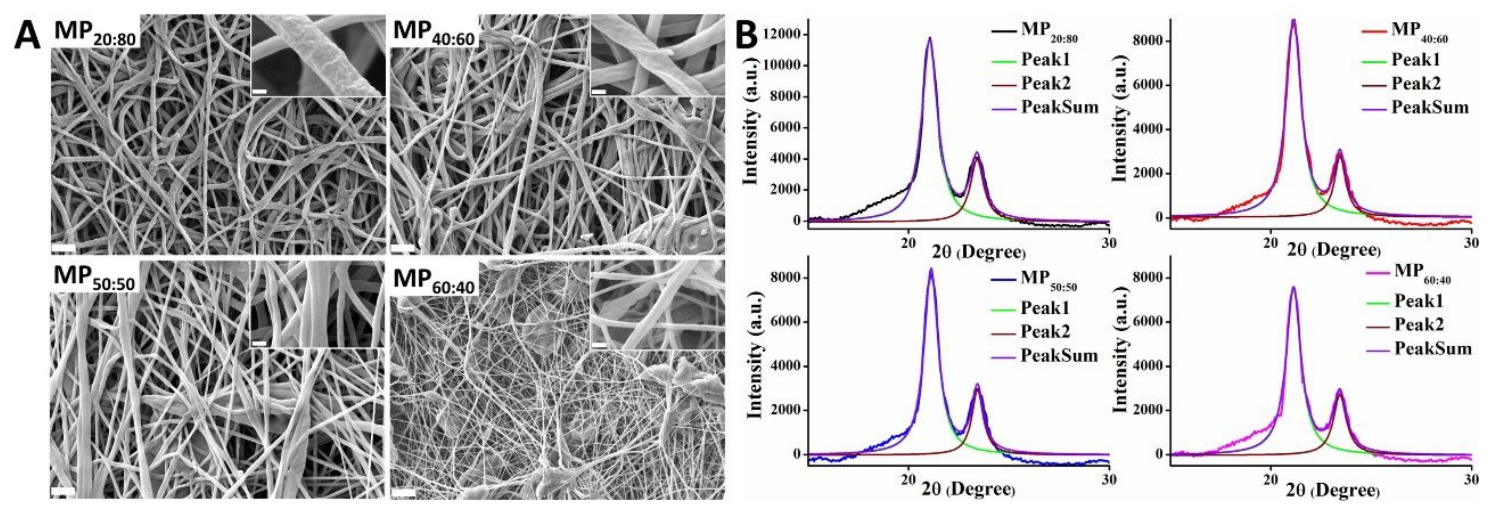

Figure 2. A. Scanning electron micrographs of various MEH:PPV:PCL nanofibers acquired at $10 \mathrm{~K}$ magnification electrospun at four volume ratios (Scale bar $=4 \mu \mathrm{m}$ ) as labelled. Inset images acquired at $150 \mathrm{~K}$ magnification (Scale bar=400 nm). B. XRD patterns of different variations of MEH:PPV:PCL nanofibers as labelled along with Voigtian fits of the XRD profiles that best describe their diffraction patterns.

Table 2. Characteristics of the XRD peaks of various MEH-PPV:PCL electrospun nanofibers corresponding to (110) and (200) planes.

\begin{tabular}{lcccc}
\hline Sample & Peaks (hkl) & $\boldsymbol{d}(\AA)$ & $\boldsymbol{L}(\AA)$ & Strain (e) (\%) \\
\hline $\mathrm{MP}_{20: 80}$ & & 4.17 & 53.87 & 0.11 \\
$\mathrm{MP}_{40: 60}$ & $(110)$ & 4.14 & 48.08 & 0.23 \\
$\mathrm{MP}_{50: 50}$ & & 4.13 & 46.46 & 0.24 \\
$\mathrm{MP}_{60: 40}$ & & 4.12 & 39.34 & 0.31 \\
\hline $\mathrm{MP}_{20: 80}$ & & 3.85 & 43.84 & 0.18 \\
$\mathrm{MP}_{40: 60}$ & $(200)$ & 3.86 & 42.31 & 0.20 \\
$\mathrm{MP}_{50: 50}$ & & 3.78 & 43.33 & 0.28 \\
$\mathrm{MP}_{60: 40}$ & & 3.75 & 40.33 & 0.35 \\
\hline
\end{tabular}

SEM showed variation in diameters of the electrospun MEH-PPV:PCL nanofibers prepared by blending at various volume ratios [Figure 2 (A)]. The diameter decreases with increase in the volume percent of MEH-PPV against PCL. At least 100 fibers were analysed for each sample and the diameters of $\mathrm{MP}_{20: 80}, \mathrm{MP}_{40: 60}, \mathrm{MP}_{50: 50}$ and $\mathrm{MP}_{60: 40}$ were 
measured to be $324 \pm 70,280 \pm 82198 \pm 30$ and $132 \pm 53 \mathrm{~nm}$. The electrospun mats with the highest MEH-PPV concentration consist of beaded fibers. The reduction in nanofiber diameter with a rise of MEH-PPV concentration is attributed to the low ability to spin. ${ }^{30,31}$

XRD study revealed two distinct peaks referring to orthorhombic crystalline structures of PCL at $2 \theta=21.5^{\circ}$ and $23.7^{\circ}$ corresponding to (110) and (200) planes [Figure 2 (B)]. ${ }^{32}$ In fact, the characteristics diffraction peak of MEH-PPV overlaps at $2 \theta=21.5^{\circ}$ corresponding to the (110) plane of the monoclinic unit cell of the PPV crystal. ${ }^{33,34} \mathrm{MEH}-$ PPV shows three additional diffraction peaks at $2 \theta=13.1^{\circ}, 15.6^{\circ}$ and $28.2^{\circ}, 35$ which appeared in our study with exceedingly small intensities as compared to PCL due to reduced MEH-PPV content $(0.5 \mathrm{wt} \%)$ versus PCL $(14 \mathrm{wt} \%)$. Thus, the crystallinity of the electrospun mats is dominated by crystalline nature of PCL than that of MEH-PPV. This is evident from the detailed analysis of the XRD patterns by single line approximation technique employing Voigt function, which suggests longer domain for the electrospun nanofibers having higher volume percent of PCL such as $\mathrm{MP}_{20: 80}$ and

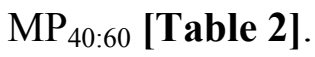

\subsection{Current-voltage (IV) characteristics}
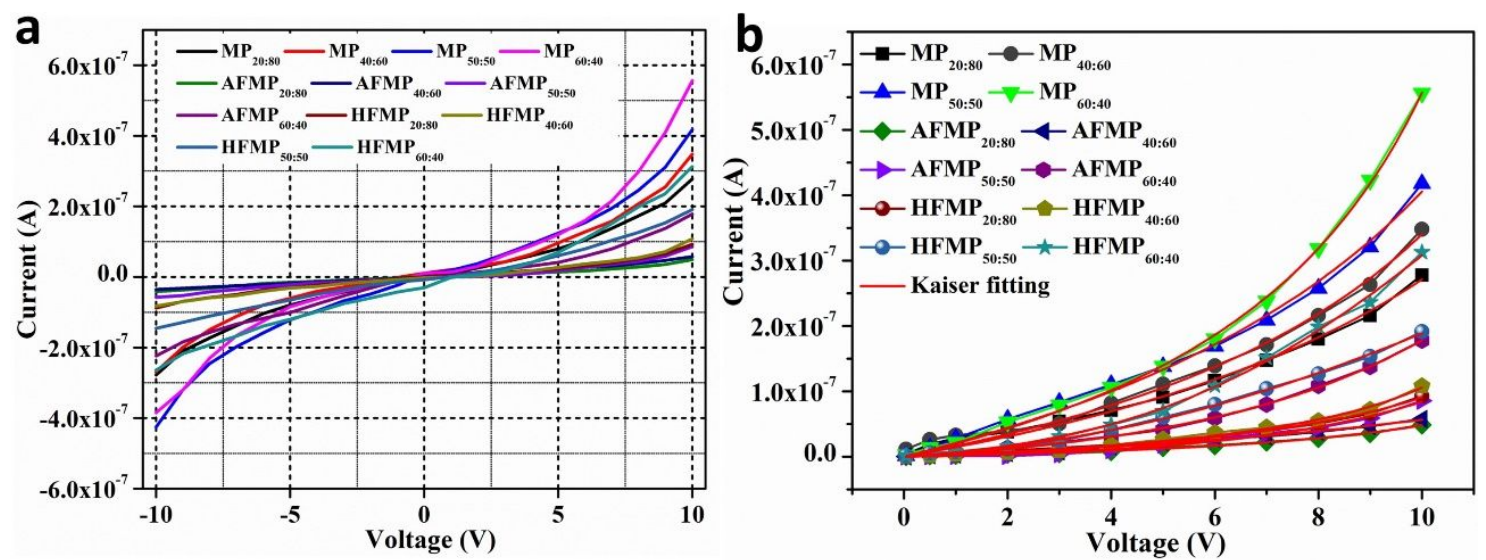

Figure 3. a. IV characteristics and b. Kaiser fits (forward bias) of non-functionalized and functionalized MEH-PPV:PCL electrospun nanofibers.

The electrospun nanofibers showed stochastic IV characteristics but symmetrical to both polarities in the bias voltage spectrum from $-10 \mathrm{~V}$ to $+10 \mathrm{~V}$ [Figure 3 (a)]. The higher charge carrier concentration due to increased MEH-PPV content results in IV characteristics with greater current, i.e., $\mathrm{MP}_{60: 40}>\mathrm{MP}_{50: 50}>\mathrm{MP}_{40: 60}>\mathrm{MP}_{20: 80}$. In addition, the surface functionalized nanofibers displayed a slightly lower current at a specific bias voltage as compared to their corresponding non-functionalized nanofibers. Nonetheless, HDA functionalized nanofibers $\left(\mathrm{HFMP}_{20: 80}, \mathrm{HFMP}_{40: 60}, \mathrm{HFMP}_{50: 50}\right.$, and $\left.\mathrm{HFMP}_{60: 40}\right)$ 
exhibited improved IV characteristics than APTES functionalized nanofibers (AFMP 20:80, $\operatorname{AFMP}_{40: 60}, \mathrm{AFMP}_{50: 50}$, and AFMP $\left.60: 40\right)$.

Notably, there were no significant alterations in sheet resistance $\left(R_{s}\right)$ suggesting little changes in the conductivity of electrospun mats following surface functionalization as illustrated in Table 3. Electrospun nanofibers' sheet resistance $\left(R_{s}\right)$ decreases with increased MEH-PPV concentration, which means increased surface conductivity. Thus, $\mathrm{MP}_{60: 40}$ and its surface functionalized counterparts, i.e., $\mathrm{AFMP}_{60: 40}$ and $\mathrm{HFMP}_{60: 40}$, with lowest sheet resistance $\left(R_{s}\right)$ due to highest MEH-PPV content, have been found to be more electrically conductive as compared to the other electrospun mats. A small increase in the sheet resistance $\left(R_{s}\right)$ values of the functionalized mats without altering the nonlinearity can be ascribed to cleavage of $\pi-\pi$ staking of MEH-PPV after functionalization. Results show that surface functionalization was achieved without deteriorating MEHPPV's conductive properties.

To understand the conduction mechanism in the electrospun nanofiber, positive IV data were plotted on the log-log scale displaying two distinct linear regions: one in the low voltage $\left(0<\mathrm{V}<3\right.$ for $\mathrm{MP}_{20: 80}, \mathrm{MP}_{40: 60}, \mathrm{AFMP}_{20: 80}, \mathrm{AFMP}_{40: 60}, \mathrm{HFMP}_{20: 80}$ and $\mathrm{HFMP}_{40: 60} ; 0<\mathrm{V}<2$ for $\mathrm{MP}_{50: 50}, \mathrm{MP}_{60: 40}, \mathrm{AFMP}_{50: 50}, \mathrm{AFMP}_{60: 40}, \mathrm{HFMP}_{50: 50}$, and $\left.\operatorname{HFMP}_{60: 40}\right)$ and the other in the high voltage $\left(3<\mathrm{V}<10\right.$ for $\mathrm{MP}_{20: 80}, \mathrm{MP}_{40: 60}, \mathrm{AFMP}_{20: 80}$, $\mathrm{AFMP}_{40: 60}, \mathrm{HFMP}_{20: 80}$ and $\mathrm{HFMP}_{40: 60}$ and $2<\mathrm{V}<10 \mathrm{MP}_{50: 50}, \mathrm{MP}_{60: 40}, \mathrm{AFMP}_{50: 50}$, $\mathrm{AFMP}_{60: 40}, \mathrm{HFMP}_{50: 50}$, and HFMP $60: 40$ ) [Figure S2]. These regions were fitted according to, $\mathrm{I}=\mathrm{KV}^{\mathrm{m}}$, where $\mathrm{K}$ and $\mathrm{m}$ are constant and the slope of the fitted curve, respectively. ${ }^{36}$ At low voltage, the exponent $\left(\mathrm{m}_{1}\right)$ is almost unitary indicating linear variation of current with voltage following Ohmic charge transport mechanism. The exponent $\left(\mathrm{m}_{2}\right)$ differs from the unity at higher voltage region suggesting non-linear variation of current with voltage and the current follows space-charge limited conduction (SCLC) mechanism due to trapped charges ${ }^{37}$ At low voltage, the density of the intrinsic charge carriers is more than the injected charge carriers referring to Ohmic charge transport mechanism. With applied voltage beyond 2-3 V the density of injected charge carriers becomes equivalent to the density of thermally generated free carriers. At a particular voltage, Ohmic conduction starts to show non-Ohmic behaviour and SCLC occurs. This particular voltage is the critical voltage $\left(\mathrm{V}_{\mathrm{c}}\right)$, which is defined $\mathrm{as}^{38}$ :

$$
V_{c}=\frac{8 q p_{o} d^{2}}{9 \varepsilon_{0} \varepsilon_{r} \theta}
$$


where $\mathrm{p}_{\mathrm{o}} \mathrm{d}, \varepsilon_{\mathrm{o}}$, and $\varepsilon_{\mathrm{r}}$ are the density of thermally generated charge carrier density, thickness of the sample, permittivity of free space and dielectric constant of the sample, respectively. $\theta$ is trap factor, defined as $p /\left(p+p_{t}\right)$, where $p$ and $p_{t}$ are density of free charge carriers and trapped charge carriers, respectively, which becomes higher with increase in the free charge carrier density (p) in the sample.

Table 3. Sheet resistance $\left(R_{s}\right)$ and critical voltage $\left(V_{c}\right)$ of the pristine and functionalized MEH-PPV:PCL electrospun mats. $R_{s}$ values were expressed as Mean \pm S.D ( $\left.n=3\right)$.

\begin{tabular}{lcc}
\hline $\begin{array}{c}\text { Sample } \\
\text { name }\end{array}$ & $\begin{array}{c}\text { Sheet resistance } \\
(\mathbf{M} \boldsymbol{\Omega})\end{array}$ & $\begin{array}{c}\left.\boldsymbol{R}_{\boldsymbol{s}}\right) \\
\text { Critical voltage }\left(\mathbf{V}_{\mathbf{c}}\right)\end{array}$ \\
\hline $\mathrm{MP}_{20: 80}$ & $52.7 \pm 17.3$ & 2.81 \\
\hline $\mathrm{MP}_{40: 60}$ & $31.7 \pm 10.3$ & 2.39 \\
\hline $\mathrm{MP}_{50: 50}$ & $15.2 \pm 9.3$ & 1.90 \\
\hline $\mathrm{MP}_{60: 40}$ & $2.45 \pm 2.02$ & 1.33 \\
\hline $\mathrm{AFMP}_{20: 80}$ & $94.4 \pm 20.5$ & 3.07 \\
\hline $\mathrm{AFMP}_{40: 60}$ & $85.1 \pm 18.9$ & 2.71 \\
\hline $\mathrm{AFMP}_{50: 50}$ & $51.3 \pm 12.4$ & 2.02 \\
\hline $\mathrm{AFMP}_{60: 40}$ & $5.32 \pm 1.11$ & 1.91 \\
\hline $\mathrm{HFMP}_{20: 80}$ & $85.6 \pm 18.5$ & 3.02 \\
\hline $\mathrm{HFMP}_{40: 60}$ & $77.6 \pm 21.9$ & 2.61 \\
\hline $\mathrm{HFMP}_{50: 50}$ & $44.4 \pm 8.7$ & 2.00 \\
\hline $\mathrm{HFMP}_{60: 40}$ & $3.67 \pm 1.54$ & 1.45 \\
\hline
\end{tabular}

The critical voltages $\left(\mathrm{V}_{\mathrm{c}}\right)$ of all the electrospun nanofibers were determined from the intersection of the extended liner fit of the log-log plot [Table 3]. The $\mathrm{V}_{\mathrm{c}}$ declines with higher amount of MEH-PPV, which facilitates the higher of free charge carrier density (p) to the nanofibers resulting in improved conductivity. However, the surfacefunctionalized equivalents of the various electrospun nanofibers showed minute increase in the $V_{c}$ values, which agrees with their sheet resistance $\left(R_{s}\right)$ values. Moreover, HDA functionalized nanofibers showed smaller $V_{c}$ values than their APTES functionalized equivalents [Table 3]. Due to high density of holes and traps, MEH-PPV exhibits non- 
linear characteristics and according to Kaiser et al. such non-linearity depends on the electric field (G) applied as ${ }^{39}$ :

$$
\mathrm{G}=\frac{\mathrm{I}}{\mathrm{V}}=\frac{\mathrm{G}_{0} \exp \left(\mathrm{V} / \mathrm{V}_{0}\right)}{1+\mathrm{h}\left[\exp \left(\mathrm{V} / \mathrm{V}_{0}\right)-1\right]}
$$

where $\mathrm{G}_{0}$ is temperature dependence low field $(V \rightarrow 0)$ conductance and $\mathrm{h}=\mathrm{G}_{0} / \mathrm{G}_{\mathrm{h}}(\mathrm{h}<$ 1), where $G_{h}$ is the saturated conductance at high field. $V_{0}$ is the voltage scale factor that provides an exponential increase in conductance with increase in $\mathrm{V}$.

Table 4. Parameters of Kaiser fits of the forward IV curves of the pristine and functionalized MEH-PPV:PCL electrospun nanofibers.

\begin{tabular}{cccc}
\hline Sample & $\mathbf{G}_{\mathbf{0}}(\mathbf{S})$ & $\mathbf{V}_{\mathbf{o}}(\mathbf{V})$ & $\mathbf{h}$ \\
\hline $\mathrm{MP}_{20: 80}$ & $5.82 \times 10^{-10}$ & 2.93 & 0.017 \\
\hline $\mathrm{MP}_{40: 60}$ & $7.78 \times 10^{-10}$ & 2.56 & 0.034 \\
\hline $\mathrm{MP}_{50: 50}$ & $5.46 \times 10^{-9}$ & 2.07 & 0.031 \\
\hline $\mathrm{MP}_{60: 40}$ & $8.18 \times 10^{-8}$ & 1.42 & 0.093 \\
\hline $\mathrm{AFMP}_{20: 80}$ & $2.36 \times 10^{-10}$ & 3.31 & 0.010 \\
\hline $\mathrm{AFMP}_{40: 60}$ & $4.21 \times 10^{-10}$ & 2.87 & 0.018 \\
\hline $\mathrm{AFMP}_{50: 50}$ & $3.33 \times 10^{-9}$ & 2.28 & 0.022 \\
\hline $\mathrm{AFMP}_{60: 40}$ & $4.78 \times 10^{-8}$ & 1.87 & 0.067 \\
\hline $\mathrm{HFMP}_{20: 80}$ & $6.02 \times 10^{-10}$ & 3.11 & 0.015 \\
\hline $\mathrm{HFMP}_{40: 60}$ & $5.44 \times 10^{-10}$ & 2.68 & 0.025 \\
\hline $\mathrm{HFMP}_{50: 50}$ & $4.73 \times 10^{-9}$ & 2.12 & 0.029 \\
\hline $\mathrm{HFMP}_{60: 40}$ & $6.38 \times 10^{-8}$ & 1.51 & 0.079 \\
\hline
\end{tabular}

To determine the electrical field dependency of non-linear IV properties, the forward IV data was fitted according to Kaiser equation [Figure 3 (b)] and the fitting parameters are shown in Table 4. The results show similar trend as in the case of sheet resistance and critical voltage determination. $\mathrm{MP}_{60: 40}, \mathrm{AFMP}_{60: 40}$ and $\mathrm{HFMP}_{60: 40}$ bearing with the highest amount of MEH-PPV exhibited the greater $G_{0}$ and $h$ values amongst the other electrospun nanofibers [Table 4]. The greater $G_{0}$ value, the easier is the charge carriers hopping along the polymer, while the greater $\mathrm{h}$ values refer to the higher conductance at low field. The electrospun nanofibers exhibit slight variation in the voltage scale factor ( $V_{0}$ ) suggesting nearly identical non-linearity of their respective IV characteristics. 
3.3 Mechanical strength test
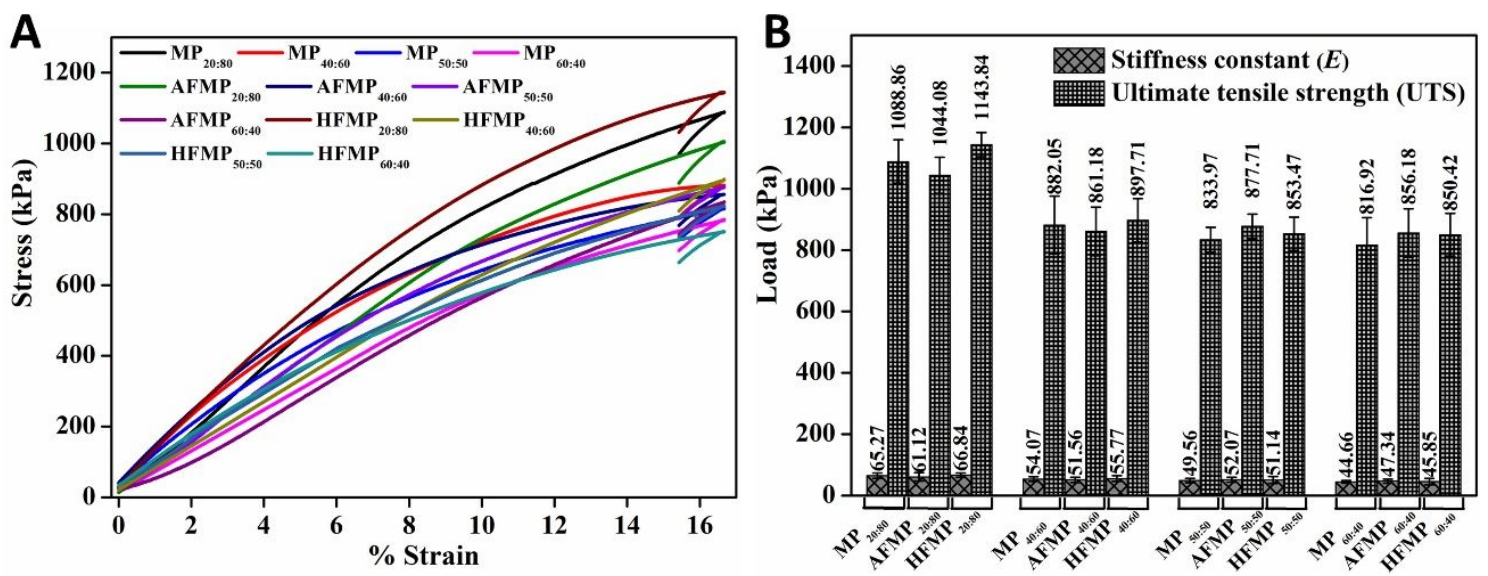

Figure 4. A. Stress-Strain behaviour; B. Stiffness constant (E) and ultimate tensile strength (UTS) of the pristine and functionalized electrospun mats.

Biomaterial scaffolds should be physically robust enough when inserted to sustain normal cell function. Accordingly, stiffness constant $(E)$ and ultimate tensile strength (UTS) of the electrospun mats were measured as shown in Figure 4 (A \& B). Nanofibrous mats with a larger fiber diameter display higher E and UTS in the order of $\mathrm{MP}_{20: 80}>\mathrm{MP}_{40: 60}>\mathrm{MP}_{50: 50}>\mathrm{MP}_{60: 40}$ and it can be attributed due to the strong junctions in thicker fibers. ${ }^{40}$ Earlier reports affirm the results that thicker nanofibers are much stiffer. ${ }^{41}$ Additionally, bead formation in the lower diameter nanofibers $\left(\mathrm{MP}_{60: 40}\right)$ accounts for its lower stiffness constant. HDA functionalized mats had greater $E$ and UTS than the non-functionalized mats, whereas APTES functionalized mats with greater amount of MEH-PPV, particularly $\mathrm{AFMP}_{50: 50}$ and AFMP $_{60: 40,}$ exhibited superior mechanical properties compared to other mats [Figure $4(B)$ ]. Surface functionalization is assumed to cause cross-linking between the polymer chains or surrounding nanofibers, which contributes to the enhanced mechanical properties of surface functionalized nanofibers. The 
findings indicate that APTES is more capable of cross-linking between the polymer chains or adjacent nanofibers with higher MEH-PPV density on the surface as in $\mathrm{MP}_{50: 50}$ and $\mathrm{MP}_{60: 40}$, while $\mathrm{HDA}$ is more effective when PCL concentration is higher. Moreover, like pristine mats, the functionalized mats also follow the idea that the nanofibrous mats with a larger fiber diameter are mechanically stronger.

\subsection{Stability test}
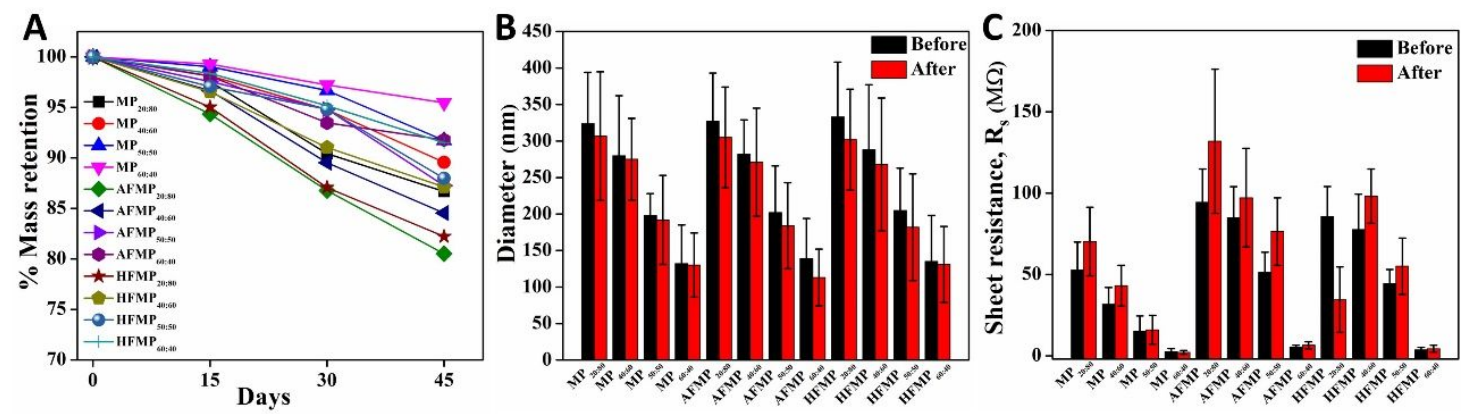

Figure 5. Stability study of the pristine and functionalized MEH-PPV:PCL nanofibers under physiological environment. A. Mass loss profile during 45 days of incubation period in neutral phosphate buffer; D. Variation in fiber diameter and E. Variation in sheet resistance $\left(R_{s}\right)$ of the nanofibrous mats before and after incubation with PBS.

An ideal electroconductive neural scaffold should possess programmable degradability and retain its conductivity in physiological environment. To validate the degradation and stability, the electrospun mats were soaked in neutral buffer for 45 days followed by SEM and I-V characteristics measurement. Degradation profile display greater mass loss of the surface functionalized mats when 
compared to that of the pristine equivalents [Figure $5(\mathrm{C})$ ], whereas SEM images do not reveal substantial degradation to the nanofibers [Figure S3]. There was a slight reduction in their diameters as compared to their non-incubated equivalents [Figure 5 (D)]. $M_{20: 80}$ and its functionalized equivalents $\left(\mathrm{AFMP}_{20: 80}\right.$ and $\mathrm{HFMP}_{20: 80}$ ) with higher percentage of PCL showed the highest mass loss of all electrospun mats. Indeed, APTES functionalized mats revealed higher mass loss as compared the HDA functionalized mats, which is due to the hydrolysis activity of APTES in PBS. ${ }^{21,42}$ The results indicate that surface functionalization contributes to increased degradability of the electrospun mats. With no substantial increase in the $R_{s}$ values after PBS incubation for 45 days [Figure 5 (E)], the electrospun mats are reasonably electrically stable under physiological condition owing the presence of a non-degraded MEH-PPV and steady PCL degradation. The findings suggest the potential of these nanofibers as an electroconductive neural scaffold.

\subsection{FT-IR spectroscopy}

Figure 6 (A \& B) displays FT-IR spectra of the non-functionalized and functionalized MEH-PPV:PCL electrospun nanofibers. All the electrospun nanofibers exhibit vibrational band characteristics for their constituents. Briefly, stretching vibrations for $\mathrm{C}=\mathrm{C}, \mathrm{C}-\mathrm{C}$, and asymmetric C-O-C in MEH-PPV appeared at 1677, 1501-1598 and 1251 $\mathrm{cm}^{-1}$, respectively ${ }^{43-45}$. The characteristics stretching vibrations in PCL were observed at 1723 and $1297 \mathrm{~cm}^{-1}$, corresponding to $\mathrm{C}=\mathrm{O}$ of ester groups and $\mathrm{C}-\mathrm{O} / \mathrm{C}-\mathrm{C}$, respectively ${ }^{46-}$ 48. The FT-IR data of pristine MEH-PPV and PCL are provided in Figure S4 in the Supporting Information with description. The aliphatic $\mathrm{CH}_{2}$ groups in MEH-PPV and PCL showed bending vibration around $729-735 \mathrm{~cm}^{-1}$. 

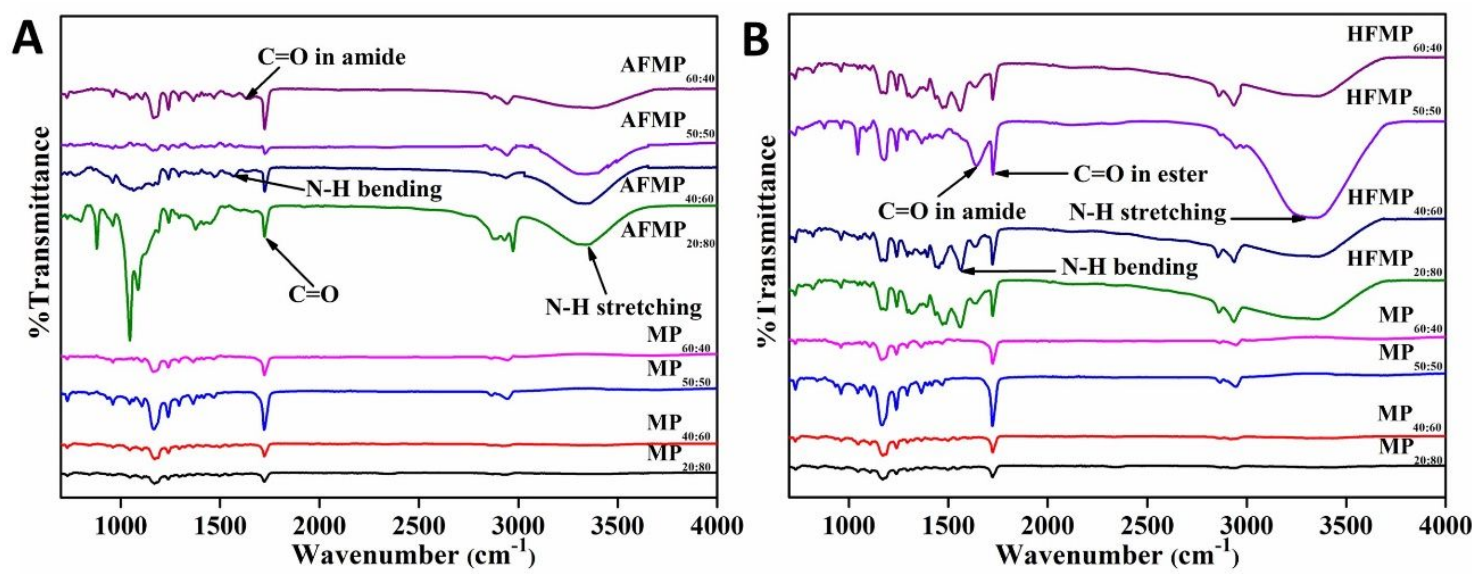

Figure 6. Vibrational spectra of MEH-PPV:PCL electrospun nanofibers before and after functionalization with A. APTES and B. HDA.

Two bands around 1560 and $3500 \mathrm{~cm}^{-1}$ of the APTES functionalized nanofibers [Figure 6 (A)], correspond to stretching of C-N-H or bending of N-H and stretching of N-H bonds, respectively. ${ }^{49}$ This provides strong proof of the amine functionality being integrated into the MEH-PPV:PCL nanofibers after APTES functionalization. The FT-IR spectra of APTES functionalized nanofibers also display a weak signal for $\mathrm{C}=\mathrm{O}$ stretching in amide as labelled in Figure 6 (A). The Si-O characteristic band in the range $1000-1100 \mathrm{~cm}^{-1}$ coincides with the PCL and MEH-PPV characteristic bands. ${ }^{50}$

The HDA functionalized nanofibers showed two bands at 1550 and $3400 \mathrm{~cm}^{-1}$, corresponding to N-H bonds in secondary (bending) and primary (stretching) amines, respectively, those were absent in the pristine nanofibers [Figure 6 (B)]. Furthermore, the distinct stretching of $\mathrm{C}=\mathrm{O}$ in amide in all HDA functionalized nanofibers indicates inclusion of amine functionalities onto the surface through amide bond formation.

3.6 X-ray photoelectron spectroscopy 
XPS was conducted to assess the chemical composition of surface of the electrospun nanofibers and to further verify amine functionality incorporation onto their surfaces following functionalization as suggested by the FT-IR study. The elemental surface composition study reveals that carbon and oxygen are the principal constituents of all nanofibers, while silicon and calcium were found as possible contamination [Figure 7(A) and Table S1]. The presence of atomic chlorine as revealed by the survey scan analysis confirms the degree of doping in MEH-PPV by $\mathrm{FeCl}_{3}$. The electrospun nanofibers and their functionalized counterparts with the highest MEH-PPV content, i.e, $\mathrm{MP}_{60: 40}$, AFMP $_{60: 40}$ and $\mathrm{HFMP}_{60: 40}$ revealed the greatest atomic percentage of $\mathrm{Cl} 2 \mathrm{p}$ viz., $1.9 \%$, $1.5 \%$ and $1 \%$, respectively [Table $\mathbf{S 1}$ ]. The lowest sheet resistance $\left(\mathrm{R}_{\mathrm{s}}\right)$ values for $\mathrm{MP}_{60: 40}$ followed by $\mathrm{AFMP}_{60: 40}$ and $\mathrm{HFMP}_{60: 40}$, are corroborated by this observation. Most notably, the appearance of nitogen (N1s) in the survey scans of APTES and HDA functionalized mats confirms amine functionalization. $\mathrm{AFMP}_{20: 80}, \mathrm{AFMP}_{40: 60}, \mathrm{HFMP}_{20: 80}$ and $\mathrm{HFMP}_{40: 60}$ actually have the highest percentage of atomic nitogen, viz. 9.8\%, 8.4\%, $15.5 \%$, and $11.3 \%$, respectively.
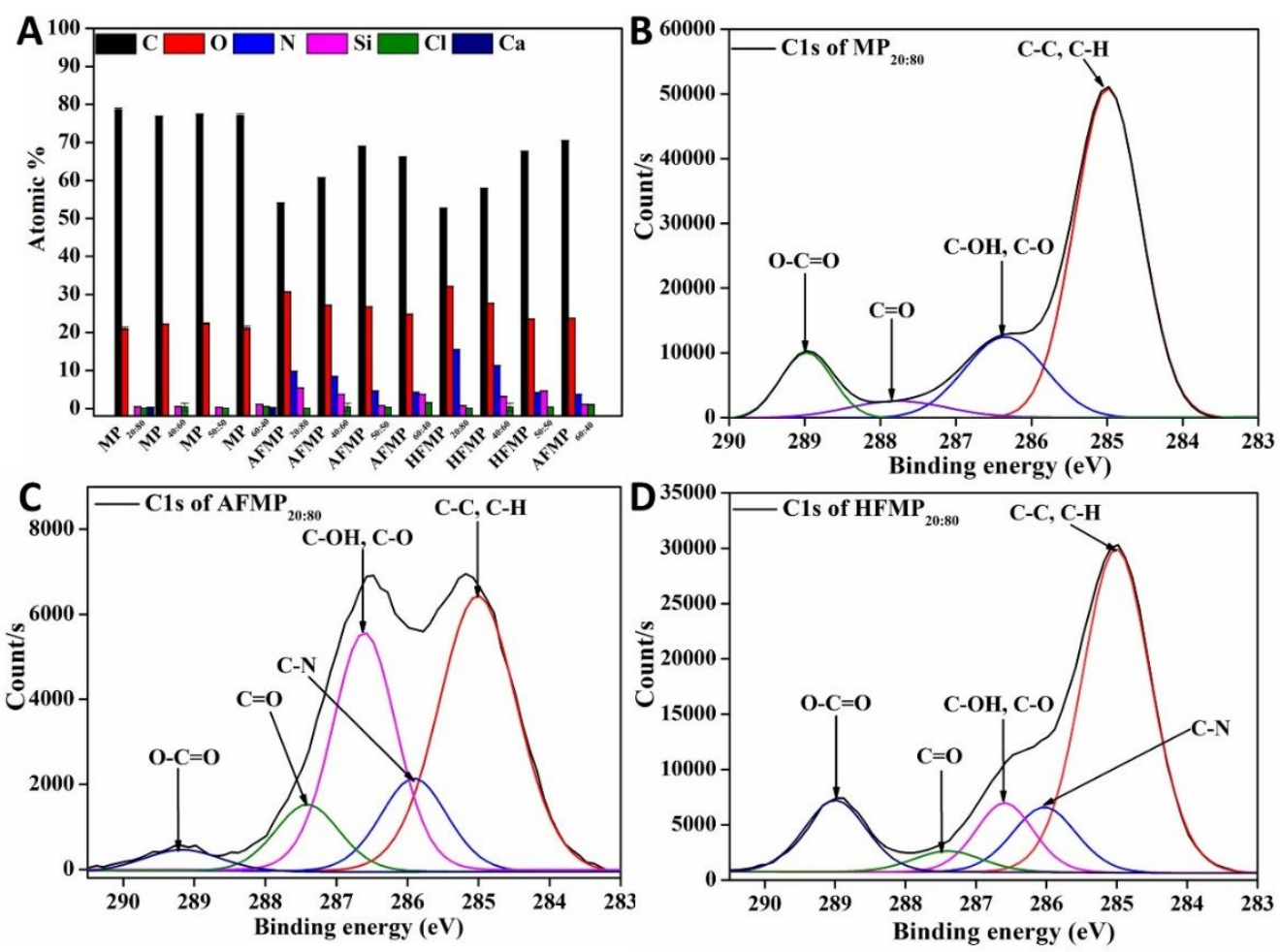

Figure 7. A. XPS survey scan results showing the surface elemental composition of the pristine and functionalized MEH-PPV:PCL electrospun nanofibers. Peak deconvolutions of C1s XPS spectra of (B) $\mathrm{MP}_{20: 80}$ (C) $\mathrm{AFMP}_{20: 80}$ and (D) $\mathrm{HFMP}_{20: 80}$. 
Table 5. Peak deconvolution results of $\mathrm{C} 1$ s narrow scan spectra of $\mathrm{MP}_{20: 80}, \mathrm{AFMP}_{20: 80}$, and $\mathrm{HFMP}_{20: 80}$.

\begin{tabular}{|c|c|c|c|c|c|c|}
\hline $\begin{array}{c}\text { Chemical } \\
\text { group }\end{array}$ & $\begin{array}{c}\text { Peak } \\
\text { BE } \\
(e V)\end{array}$ & $\begin{array}{c}\text { Atomic } \\
\% \\
\text { MP }_{20: 80}\end{array}$ & $\begin{array}{c}\text { Peak } \\
\text { BE }\end{array}$ & $\begin{array}{l}\text { Atomic \% } \\
\text { AFMP }_{20: 80}\end{array}$ & $\begin{array}{c}\text { Peak } \\
\text { BE } \\
(e V)\end{array}$ & $\begin{array}{l}\text { Atomic \% } \\
\text { HFMP }_{20: 80}\end{array}$ \\
\hline$\overline{\mathrm{C}-\mathrm{C}, \mathrm{C}-\mathrm{H}}$ & 284.99 & 65.82 & 285.17 & 44.19 & 285.02 & 57.24 \\
\hline $\mathrm{C}-\mathrm{N}$ & - & - & 285.95 & 12.69 & 286.03 & 11.5 \\
\hline$\overline{\mathrm{C}-\mathrm{OH}, \mathrm{C}-\mathrm{O}}$ & 286.35 & 16.59 & 286.51 & 30.86 & 286.60 & 10.98 \\
\hline $\mathrm{C}=\mathrm{O}$ & 287.79 & 5.03 & 287.83 & 7.68 & 287.76 & 7 \\
\hline$\overline{\mathrm{O}-\mathrm{C}=\mathrm{O}}$ & 288.96 & 12.56 & 289.22 & 4.59 & 289.02 & 12.28 \\
\hline
\end{tabular}

The representative C1s XPS spectra of $\mathrm{MP}_{20: 80}, \mathrm{AFMP}_{20: 80}$, and $\mathrm{HFMP}_{20: 80}$ are depicted in Figure 7 (B-D), and the peak deconvolution data are presented in Table 5. The peak deconvolution showed evolution of a new peak referring to $\mathrm{C}-\mathrm{N}$ species at 285.86 and $286.02 \mathrm{eV}$ in the $\mathrm{C} 1 \mathrm{~s}$ spectra of $\mathrm{AFMP}_{20: 80}$ and $\mathrm{HFMP}_{20: 80}$, respectively [Figure 7 (C \& D)]. ${ }^{51-54}$ Substantial increase in the atomic percentage of $\mathrm{C}-\mathrm{O}$ species in the $\mathrm{C} 1 \mathrm{~s}$ spectrum of AFMP $20: 80$ suggests APTES incorporation on the surface as the APTES molecule has three C-O bonds. The results indicate that surface functionalization using APTES and HDA successfully incorporated amine groups on the surface of MEH-PPV:PCL nanofibers. In addition, the $\mathrm{MP}_{20: 80}, \mathrm{AFMP}_{20: 80}$ and $\mathrm{HFMP}_{20: 80} \mathrm{C} 1 \mathrm{~s}$ spectra consist of two common peaks for $\mathrm{O}=\mathrm{C}-\mathrm{O}$ and $\mathrm{C}=\mathrm{O}$ bonds in ester groups of $\mathrm{PCL}^{52,55}$ and amide in $\mathrm{DMF}$, used during electrospinning, respectively. DMF possesses low evaporation rate $^{56}$ and hence, a small concentration of DMF may remain even after the electrospun nanofibers were air dried for $24 \mathrm{~h}$. Furthermore, the rigorous washing of the samples with deionized water prior to XPS characterization, was also not able to remove DMF and it is obvious as strong acids and bases can only hydrolyse DMF at elevated temperatures. ${ }^{56}$ Thus, the $\mathrm{C}=\mathrm{O}$ species, common to all electrospun mats, comes from DMF amide only.

3.7 Probable mechanisms of surface functionalization

FT-IR and XPS analysis confirmed the surface amination of MEH-PPV:PCL mats and on that basis, the interaction mechanisms of APTES/HDA with PCL and MEH-PPV are shown in Figure 8 and Figure 9, respectively. As the electrospun mats are mixture of 
MEH-PPV and HDA, surface functionalization is anticipated to induce MEH-PPV and PCL aminolysis concurrently.

\section{Scheme I}

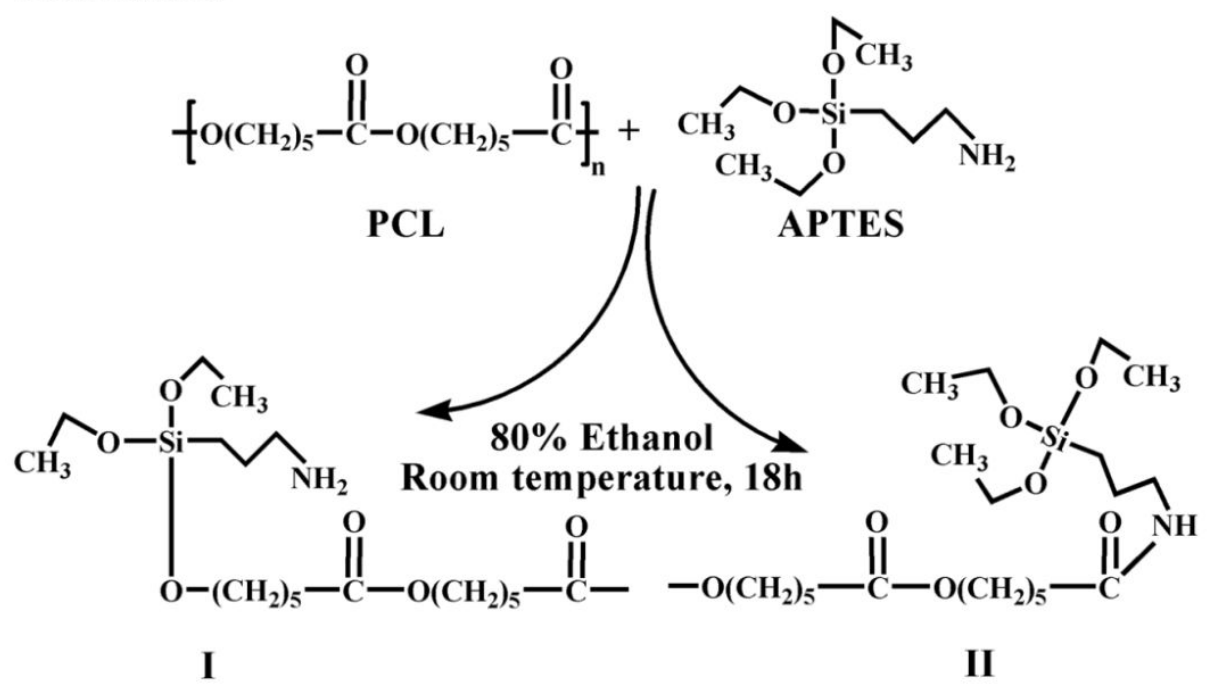

\section{Scheme II}

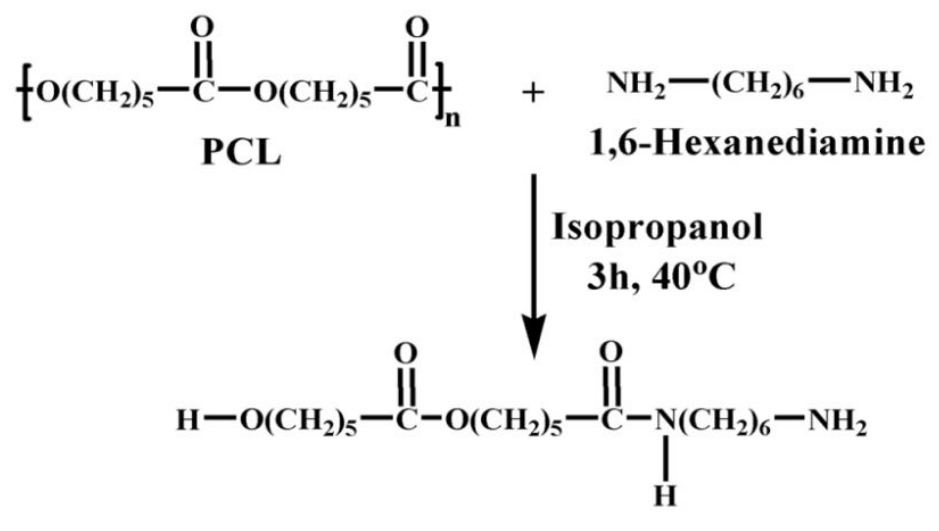

III

Figure 8. Proposed scheme of interactions of PCL with APTES (Scheme I) and HDA (Scheme II) as suggested by FT-IR and XPS analysis. 
Scheme III

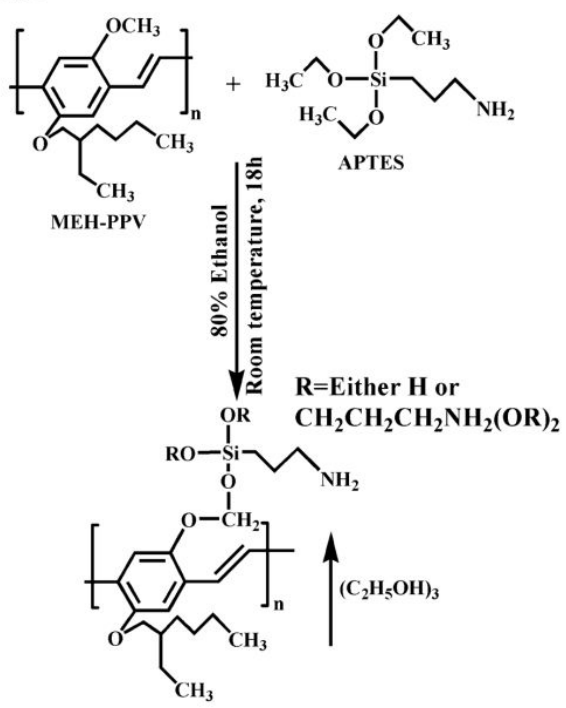

IV
Scheme IV

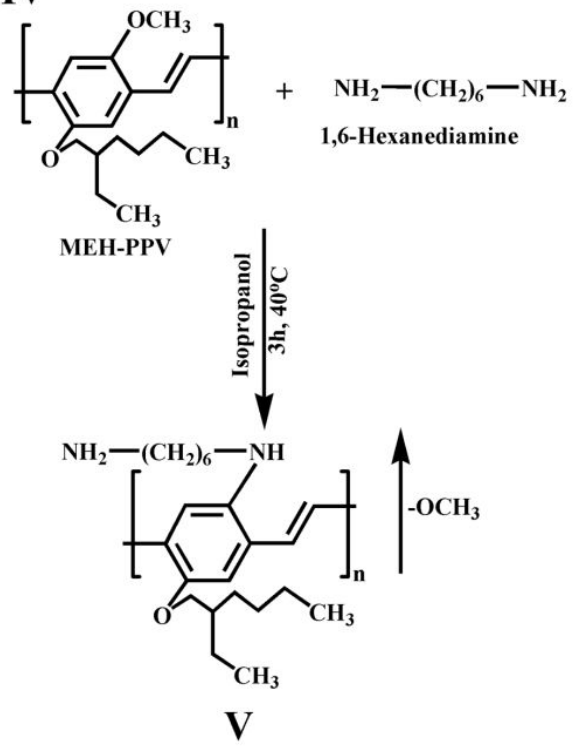

Figure 9. Proposed scheme of interactions of MEH-PPV with APTES (Scheme III) and HDA (Scheme IV) as suggested by FT-IR and XPS analysis.

We suggest interaction between APTES and PCL through Si-O-C (Complex I) and amide bond (Complex II) [Figure 8]. APTES easily hydrolyzes to ethanol and trisilanol in an aqueous medium ${ }^{57}$. Si-C bonding of APTES is hydrolytically stable, while ethoxy groups linked to Si are readily hydrolysable $21,23,44,58$. Hence, surface functionalization process may result in unsaturated $\mathrm{Si}$ in contrast to the hydrolysis of the ethoxy groups. Thus, the plentiful ester groups (-COO-) in PCL can easily interact with the APTES via Si-O-C bond formation giving the complex I [Scheme I of Figure 8]. The emergence of Si-O bonds with relatively higher intensities in the FT-IR spectra of APTES functionalized nanofibers confirms this hypothesis. In addition, greater concentration of $\mathrm{C}=\mathrm{O}$ of amide observed in the XPS spectra of AFMP $20: 80$ suggests that primary amine $\left(-\mathrm{NH}_{2}\right)$ of APTES interacts with the ester groups in PCL secondary amide bond (-CONH-). This gives complex II as depicted in [Scheme I of Figure 8]. The ester groups of PCL may also form amide bond with HDA giving complex III as depicted in Scheme II [Figure 8]. The appearance of $\mathrm{C}=\mathrm{O}$ stretching $\left(1640 \mathrm{~cm}^{-1}\right)$ and $\mathrm{N}-\mathrm{H}\left(1550 \mathrm{~cm}^{-1}\right)$ bending in amide appeared in the FT-IR and the characteristics BE for $\mathrm{C}=\mathrm{O}$ in amide in the XPS spectra of the HDA functionalized nanofibers, confirms the above claim.

Earlier report suggested that APTES can hydrolyse readily in $80 \%$ of ethanol ${ }^{59}$. Therefore, APTES interacts with methoxy group in phenylene ring of MEH-PPV and 
forms the complex IV [Scheme III of Figure 9]. This observation is confirmed by the increased intensity of Si-O bond around $1000-1100 \mathrm{~cm}^{-1}$ in the FT-IR as well as greater C-O species concentration in the XPS of the APTES functionalized mats. On the otherhand, the amino groups of HDA may react with MEH-PPV through formation of a tetrahedral intermediate as shown in Scheme IV ${ }^{60}$. Next, formation of new C-N bond is taken place after removal of the methoxy group of MEH-PPV and forms the complex V [Figure 9].

\section{Biological characterizations}

4.1. MTS proliferation assay
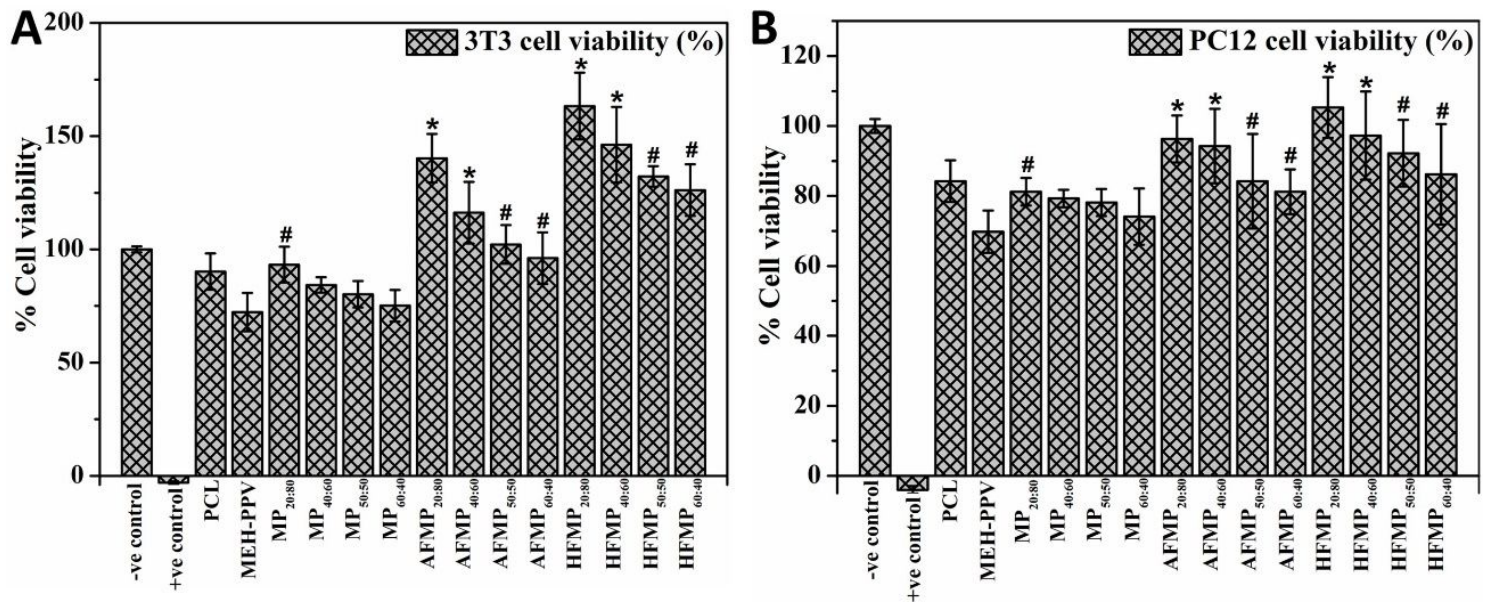

Figure 10. (A) $3 \mathrm{~T} 3$ and (B) PC12 cell viability on the pristine and functionalized MEHPPV:PCL electrospun mats after 24 h culture period (-ve control: TCP and +ve control: tert butyl maleate). \%Cell viability was expressed as Mean \pm S.D, $n=4$. Statistical significance at $\mathrm{p} \leq 0.01$ and $\mathrm{p} \leq 0.05$ between the pristine and functionalized mats are denoted as * and ${ }^{\#}$, respectively.

The impact of surface functionalization on the cytocompatibility of different electrospun mats was assessed by growing 3T3 fibroblasts and PC12 cells on them including pristine MEH-PPV and PCL. Pristine MEH-PPV and PCL revealed around 70\% and more than $80 \%$ of cell viability (3T3 and PC12 cells), respectively [Figure 10 (A \& B)]. Although pristine MEH-PPV showed cell viability slightly less than $80 \%$, the standard cell viability value generally shown by biocompatible materials, ${ }^{61}$ its cytocompatibility was improved significantly $(\mathrm{p} \leq 0.01)$ when blended with PCL. The non-functionalized nanofibers demonstrated decreased cell viability with increase in MEH-PPV content, which also indicates less cytocompatibility of MEH-PPV. Intriguingly, the functionalized mats showed more than $100 \%$ of $3 \mathrm{~T} 3$ cell viability and more than $80 \%$ PC12 cell viability 
[Figure $10(\mathbf{A} \& \mathbf{B})]$. The findings indicate that the surface functionalization contributed positively towards enhanced cell viability. The observed cell viability on the surface functionalized mats is statistically distinct from their pristine counterparts at $p \leq 0.01$ (for $\mathrm{MP}_{20: 80}$ vs AFMP $20: 80, \mathrm{MP}_{\text {20:80 }}$ vs HFMP $20: 80, \mathrm{MP}_{40: 60}$ vs AFMP $\mathrm{AP}_{40: 60}, \mathrm{MP}_{40: 60}$ vs HFMP 40:60) and at $\mathrm{p} \leq 0.05$ (for $\mathrm{MP}_{50: 50}$ vs $\mathrm{AFMP}_{50: 50}, \mathrm{MP}_{60: 40}$ vs $\mathrm{HFMP}_{60: 40}, \mathrm{MP}_{50: 50}$ vs $\mathrm{AFMP}_{50: 50}$, $\mathrm{MP}_{60: 40}$ vs HFMP $60: 40$ ). The enhanced cell viability on the largest electrospun nanofibers, i.e., $\mathrm{MP}_{20: 80}, \mathrm{AFMP}_{20: 80}$ and $\mathrm{HFMP}_{20: 80}$ is statistically different from that on the smallest electrospun nanofibers, i.e., $\mathrm{MP}_{60: 40}, \mathrm{AFMP}_{60: 40}$ and $\mathrm{HFMP}_{60: 40}(\mathrm{p} \leq 0.01)$. Likewise, there is statistical difference between $\mathrm{AFMP}_{40: 60}$ vs $\mathrm{AFMP}_{60: 40}, \mathrm{HFMP}_{40: 60}$ vs $\mathrm{HFMP}_{60: 40}$, AFMP $_{50: 50}$ vs $\mathrm{AFMP}_{60: 40}$ and $\mathrm{HFMP}_{50: 50}$ vs $\mathrm{HFMP}_{60: 40}$ at $\mathrm{p} \leq 0.05$. Although previous studies suggested larger nanofibers support better cell viability ${ }^{62,63}$, the underlying reasons behind such behaviour in the present work, do not include only the variation in fiber diameter, but also the MEH-PPV content, which alone showed lower cell viability. Moreover, larger nanofibers have higher PCL content (showed $<80 \%$ cell viability alone). Therefore, higher PCL content with reduced MEH-PPV concentration and fiber diameter, all these aided for improved cell viability. Additionally, the HDA functionalized mats supported better 3T3 and PC12 cell survival as compared to the APTES functionalized mats and the difference is statistically distinct $(\mathrm{p} \leq 0.01)$. Thus, the MTS results indicate that incorporation of APTES and HDA enhance the cytocompatibility of the electrospun mats suggesting their potential as tissue scaffold with surface functionalization. The mats also exhibited improved hemocompatibility after surface amination as revealed by the hemolysis activity assay [Figure S5].

\subsection{T3 fibroblasts behaviour}

\subsubsection{Live-dead imaging}

Live-dead assay was conducted to assess the impact of surface functionalization upon cellular morophology, adhesion and spreading at two time points, i.e., 24 and 48 h. Viable cells appeared green on different nanofibrous mats with only neglible dead cells appearing in red, which again suggest the cytocompatibility of these electrospun mats. DAPI staining is visible in only a few nuclei (blue) since staining was performed without cell fixation. The cells grown on the surface functionalized mats were more flattened or polygonal or elongated than those on the non-functionalized mats, which is more prominent after $48 \mathrm{~h}$ [Figure 11 (A)]. For verification, the average cell area and percent cell spreading were determined based on the live-dead imaging and are presented in 
Figure 11 (B \& C). TCP and PCL as controls were also examined [Figure S6 (A)]. The cells adopting flattened or polygonal or elongated shape were considered as spreading cells and spreading was more prominent on the functionalized mats than that on the nonfunctionalized mats, which is statistically distinct after $24 \mathrm{~h}(\mathrm{p} \leq 0.05)$ and $48 \mathrm{~h}(\mathrm{p} \leq 0.01)$ [Figure 11 (B)]. The average cell area was also greater on the functionalized mats than that on the non-functionalized peers and statistical significance exists after $24 \mathrm{~h}(\mathrm{p} \leq 0.05)$ and $48 \mathrm{~h}(\mathrm{p} \leq 0.01)$ [Figure 11 (C)]. The functionalized mats showed higher viable cell density as compared to the pristine mats [Figure S6 (B)].

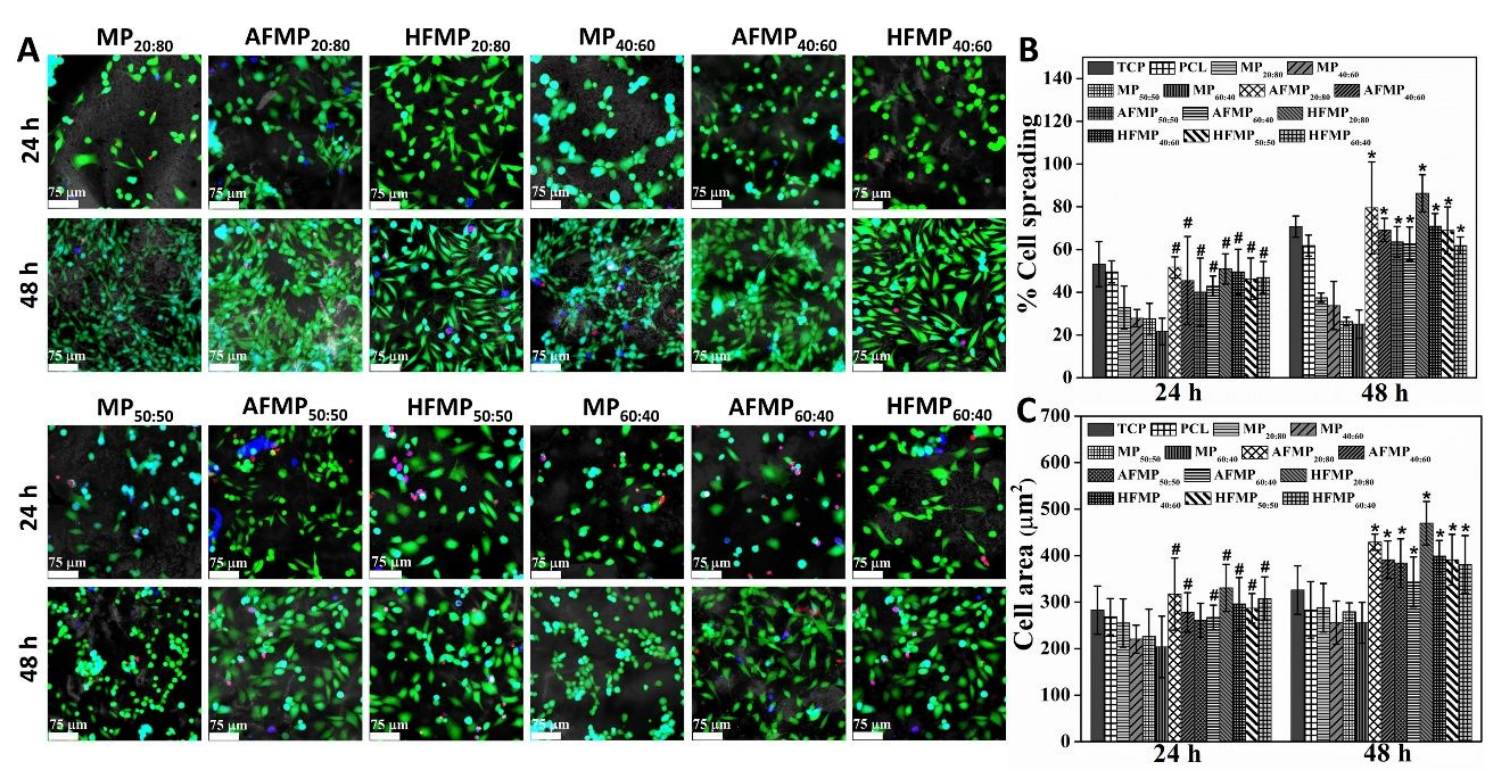

Figure 11. A. Live-dead imaging data of $3 \mathrm{~T} 3$ fibroblasts with phase contrast overlay stained with calcein AM (green), EthD-1 (red) and DAPI (blue) [Scale bar=75 $\mu \mathrm{m}$ ] and quantitative analysis of (B) percentage of cell spreading and (C) cell area (mean area of single cell) on the pristine and functionalized MEH-PPV:PCL mats after 24 and $48 \mathrm{~h}$. Data in (B) and (C) are Mean \pm S.D, $n=6 .{ }^{*}$ and ${ }^{\#}$ refer statistically significance at $p \leq 0.01$ and $\mathrm{p} \leq 0.05$, respectively.

The quatitative analysis further reveals that the cell spreading, average cell area and density were better on the functionalized mats than those on the control TCP and PCL mat at a statistical significance of $p \leq 0.01$ after $48 \mathrm{~h}$. The enhanced fibroblasts activity functionalized mats is due to the introduction of amine functional groups, which results in beneficial interaction with the cell surface. In addition, HDA functionalized mats demonstrated improved cellular activity in terms of cell apreading, projected cell area, and cell proliferation (cell density) as compared to APTES functionalized mats ( $\mathrm{p} \leq 0.01)$. 
It has also been found that the electrospun mats supported better cellular activities with an increase in PCL content (lower MEH-PPV concentation) and fiber diameter at a statistical significance of $\mathrm{p} \leq 0.05$.

\subsection{2 $3 \mathrm{~T} 3$ cell adhesion test}
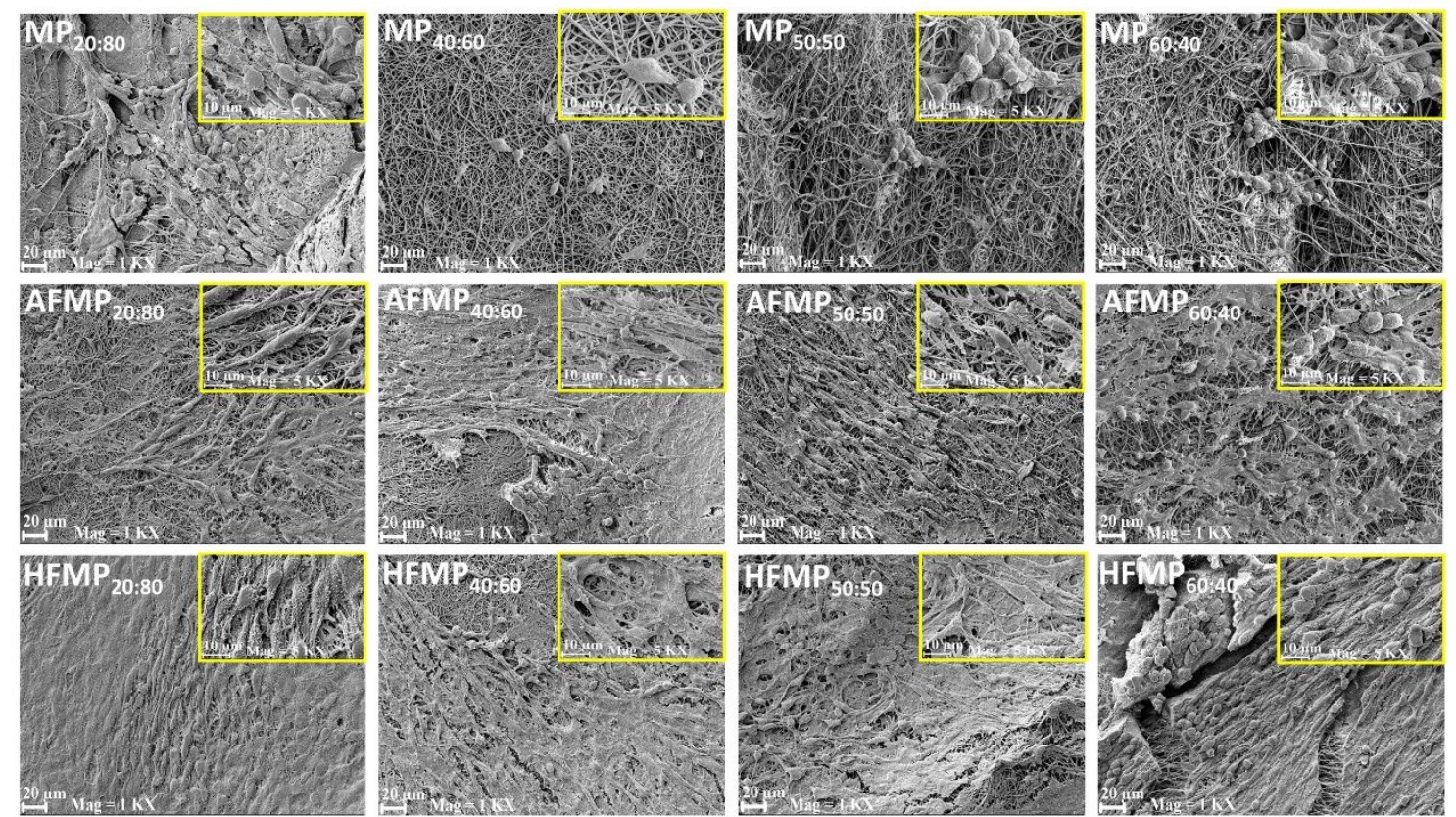

Figure 12. Morphology of $3 \mathrm{~T} 3$ fibroblasts grown on non-functionalized and functionalized MEH-PPV:PCL electrospun mats for $72 \mathrm{~h}$ [Scale bar=20 $\mu \mathrm{m}$ ]. Insets show magnified images with filopodia/lamellipodia like extensions [Scale bar=10 $\mu \mathrm{m}$ ].

To evaluate the cell adhesion, SEM analysis was conducted of 3T3 fibroblasts cells grown for $72 \mathrm{~h}$ days on different electrospun mats and the results are shown in Figure 12. The cells appeared to adhere and spread evenly on the functionalized mats as compared to the non-functioned mats, where cells with round morphology formed clusters. While nanofibers are oriented in random directions, the cells are aligned on the functionalized mats in some particular directions with simultaneous formations of filopodium and lamellipodium like extensions [Insets of Figure 12]. This finding indicated that the cells interacted favourably with the surrounding fibers of the functionalized mats and began migrating along the porous nanofiber network. Surface functionalization induced amino groups provided adequate active sites for integrin proteins to bind and form focal adhesions, supported by the presence of filopodium and lamellipodium-like extensions. This ultimately accelerated cellular activities like adhesion, spreading and migration. By comparison, due to the lack of availability of sufficient bioactive sites, non-functionalized 
mats had lower cell adhesion and morphology than functionalized mats. However, possible serum protein adsorption by the fibers might have provided minimal focal adhesions for cell adhesion ${ }^{64}$, which contributed towards the observed cell adhesion on the pristine electrospun mats. In addition, the SEM analysis indicated that cells on HDA functionalized mats were bigger and elongated than those on the APTES functionalized mats, which corroborates the live-dead results. The results revealed that surface functionalized mats offer a bioactive 3D nanofibrous architecture for fibroblast adhesion, proliferation and spreading via contact guidance. ${ }^{62}$

\subsection{PC12 cell behaviour}

\subsubsection{Beta (III) tubulin immunochemistry}
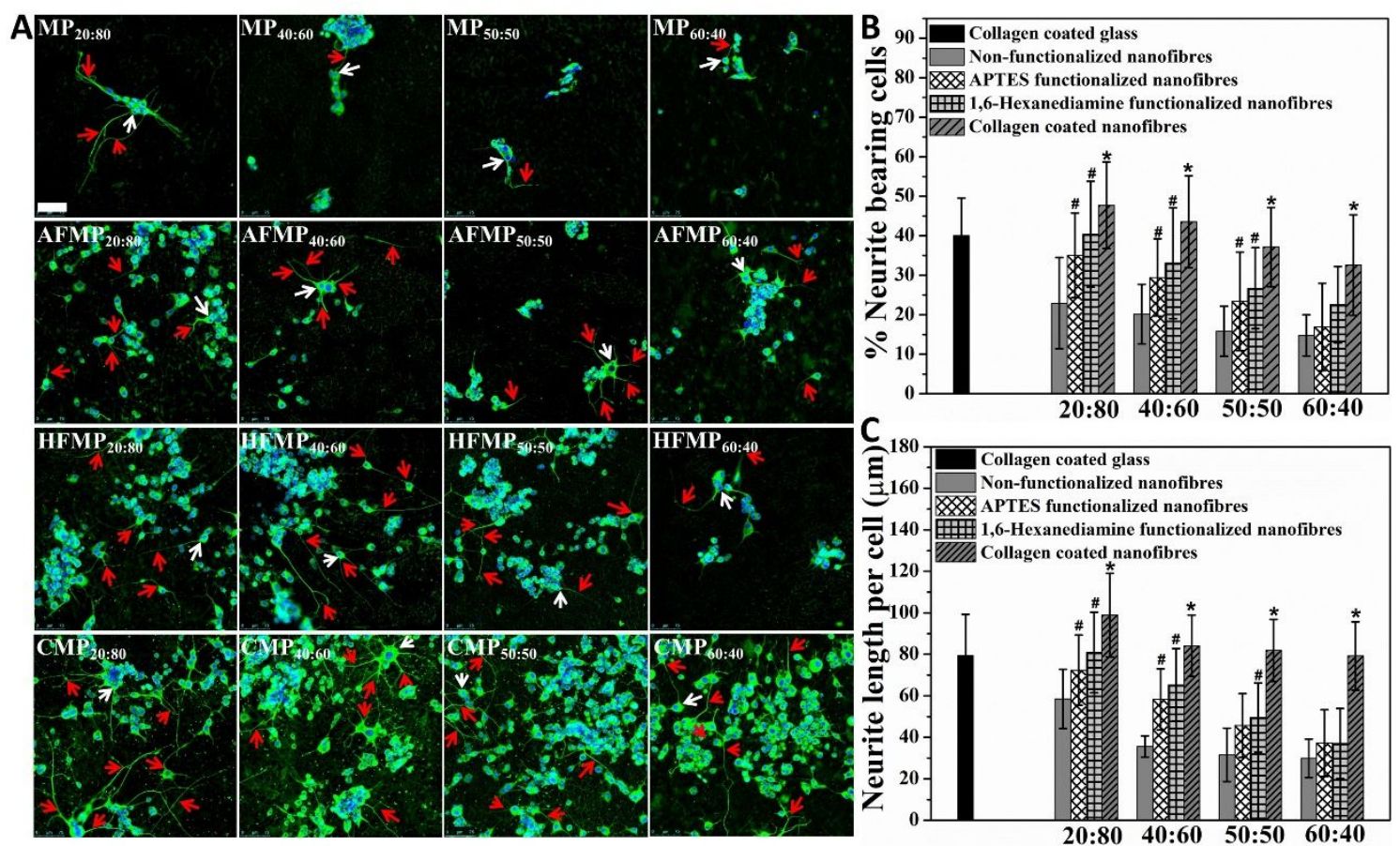

Figure 13. (A) Tubulin immunostaining of PC12 cells cultured under differentiating condition on for 7 days with DAPI counterstaining on various MEH-PPV:PCL mats as labelled. Neuronal cell bodies are represented with white arrows, while red arrows indicate neurons with elongated and branched neurites with or without growth cones [Scale bar $=75 \mu \mathrm{m}]$. Quantification of neurite development and extension presented as (B) \% neurite-bearing cells and (C) neurite length per cell (average neurite length). * and \# refer statistical significance from the pristine mats at $\mathrm{p} \leq 0.01$ and $\mathrm{p} \leq 0.05$, respectively.

To verify the neuronal differentiation on various versions of MEH:PCL electrospun mats, PC12 cells were immunostained by beta (III) tubulin antibody for visualization of 
cytoskeletal microtubules $^{65}$, which is shown in Figure 13(A). The neural phenotype of the differentiated cells is more coherent on the collagen coated mats than that on the uncoated (pristine and functionalized) mats. Most of the cells on the collagen coated mats had lengthy neurites with/without branching, variable-sized circular somas and several growth cones. Slightly lesser in extent, the uncoated functionalized electrospun mats demonstrated neuronal differentiation. In contrast, the uncoated non-functionalized mats showed extremely poor neuronal characteristics of PC12 cells grown on them owing to poor cell adhesion. The average cell density determined from DAPI-stained nuclei counting on four quarters of each sample $(n=3)$ indicate weaker cell adhesion on the uncoated non-functionalized mats than that on the functionalized and collagen coated mats [Figure S8]. Cell density on the surface functionalized mats was better than that on the pristine mats $(\mathrm{p} \leq 0.05)$. Highest PC12 cell attachment was seen on the collagen coated mats ( $\mathrm{p} \leq 0.01$ to pristine mats), which is consistent with our previous report. ${ }^{15}$ There is also a statistically significant difference in cell numbers between larger nanofibers $\left(\mathrm{AFMP}_{20: 80}\right.$ and $\left.\mathrm{HFMP}_{20: 80}\right)$ and relatively smaller nanofibers $\left(\mathrm{AFMP}_{50: 50}, \mathrm{AFMP}_{60: 40}\right.$, HFMP $_{50: 50}$ and $\mathrm{HFMP}_{60: 40}$ ) at $\mathrm{p} \leq 0.01$. Similarly, a difference was noted between $\mathrm{CMP}_{20: 80}$ and $\mathrm{CMP}_{60: 40}$. Thus, this finding also suggests that nanofibers with lower MEH-PPV content (higher PCL content) supported better cellular adhesion.

To measure neurite development and elongation, at least 500 cells and 300 neurites were evaluated on collagen-coated and functionalized mats, while approximately 250 cells and 150 neurites on the non-functionalized mats could be analyzed due to poor cell attachment. Neurite length longer than two cell bodies was considered for analysis. ${ }^{65,66}$ The surface functionalized mats demonstrated better neurite development and neurite elongation as compared to the pristine mats, although collagen coated mats exhibited relatively better results as shown in Figure 13 (B \& C). The percentage of cells those formed neurites and their length on the functionalized mats are substantially higher as compared to the pristine mats $(\mathrm{p} \leq 0.05)$. Notwithstanding the evidence of better outcome in terms of neurite development on collagen coated mats, no statistical difference exists when compared with the functionalized mats. In addition, HDA functionalized mats showed consistently improved neurite formation and growth than those on the APTES functionalized mats with no significant difference. Similar to results obtained with 3T3 fibroblasts, PC12 activities were upregulated with a statistically insignificant increase in fiber diameter. The surface functionalized mats (particularly AFBEN1 and HFBEN1) and the collagen coated mats showed almost comparable or better neural differentiation and 
neurite outgrowth as compared to collagen coated coverslips [Figure 13 (B \& C)]. The findings suggest surface functionalization by HDA or APTES leads to equal enhancement in PC12 cell attachment, differentiation, and neurite outgrowth than the pristine mats. The surface functionalization induced amino groups on the surface lead to favourable electrostatic interactions between the biomaterial surfaces and the cell surfaces or covalent interaction via amide bond. ${ }^{67,68}$

\subsubsection{PC12 cell adhesion test}

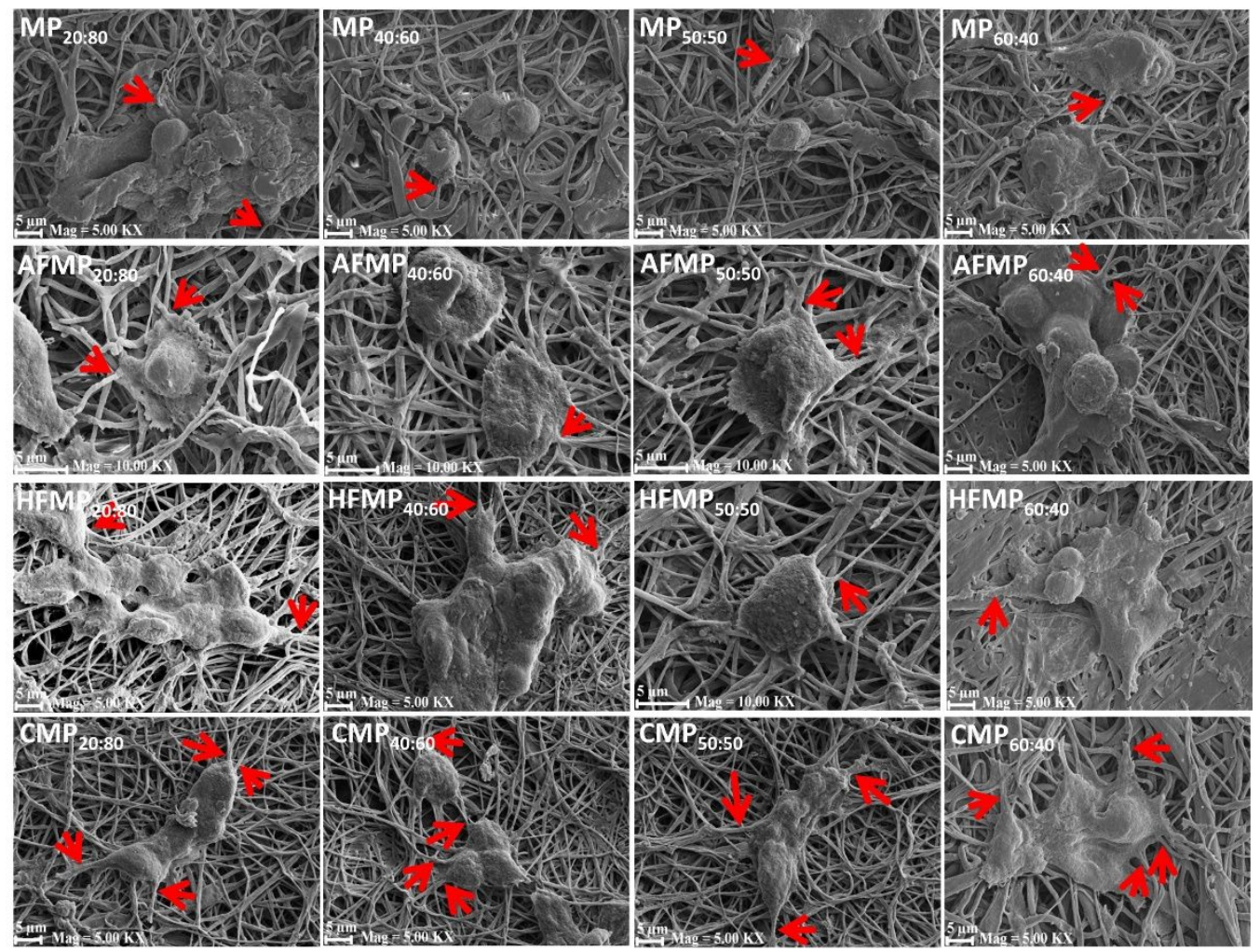

Figure 14. SEM images of PC12 cells grown for one week on various MEH-PPV:PCL mats as indicated. Red arrows indicate projections of neurites on various electrospun mats. Scale bar $=5 \mu \mathrm{m}$.

PC12 cells, grown on various electrospun mats for one week in, were characterized by SEM to validate the cell adhesion and morphology [Figure 14]. Cells adhere nicely onto the functionalized mats as compared to the non-functionalized mats, while the collagen coated mats show best cell adhesion. PC12 cells build rapport with multiple fibers and acquire elliptical morphology with prominent neurite development on the functionalized and collagen coated mats, while cells have sperical or round and distorted morphologies with few or no neurite projections on the non-functionalized mats. SEM further reveals that the cells on the functionalized mats were larger as compared to the others. The 
moderately enhanced PC12 cell adhesion and neurite growth on the functionalized electroconductive mats indicates their potential as neural scaffold.

\subsection{Electrically stimulated neurite development}

The surface functionalized mats showed substantial enhancement in 3T3 fibroblasts activities, while moderately improved PC12 differentiation. Given the intrinsic electrical conductivity of MEH-PPV:PCL mats, there is a scope to enhance the neuronal characteristics of PC12 cells grown on these scaffolds in combination with external ES to achieve the outcome like on the collagen coated mats. To validate this hypothesis, an electric voltage of $500 \mathrm{mV} / \mathrm{cm}$ for $2 \mathrm{~h}$ /day was delivered to the PC12 cells cultured on different electrospun mats for 3 continuous days and the findings are shown in Figure 15 (A). Electrically stimulated PC12 cells displayed improved neurite development including elongation and branching compared to the non-stimulated cells. Particularly, the surface functionalized mats demonstrate substantial enhancement in neurite development and elongation under the application of ES as compared to when no ES was applied. The confocal images were analysed using ImageJ software for quantitative evaluation of the neural differentiation and neurite outgrowth under the application of ES in vitro and the results are displayed in Figure 15 (B-E). 

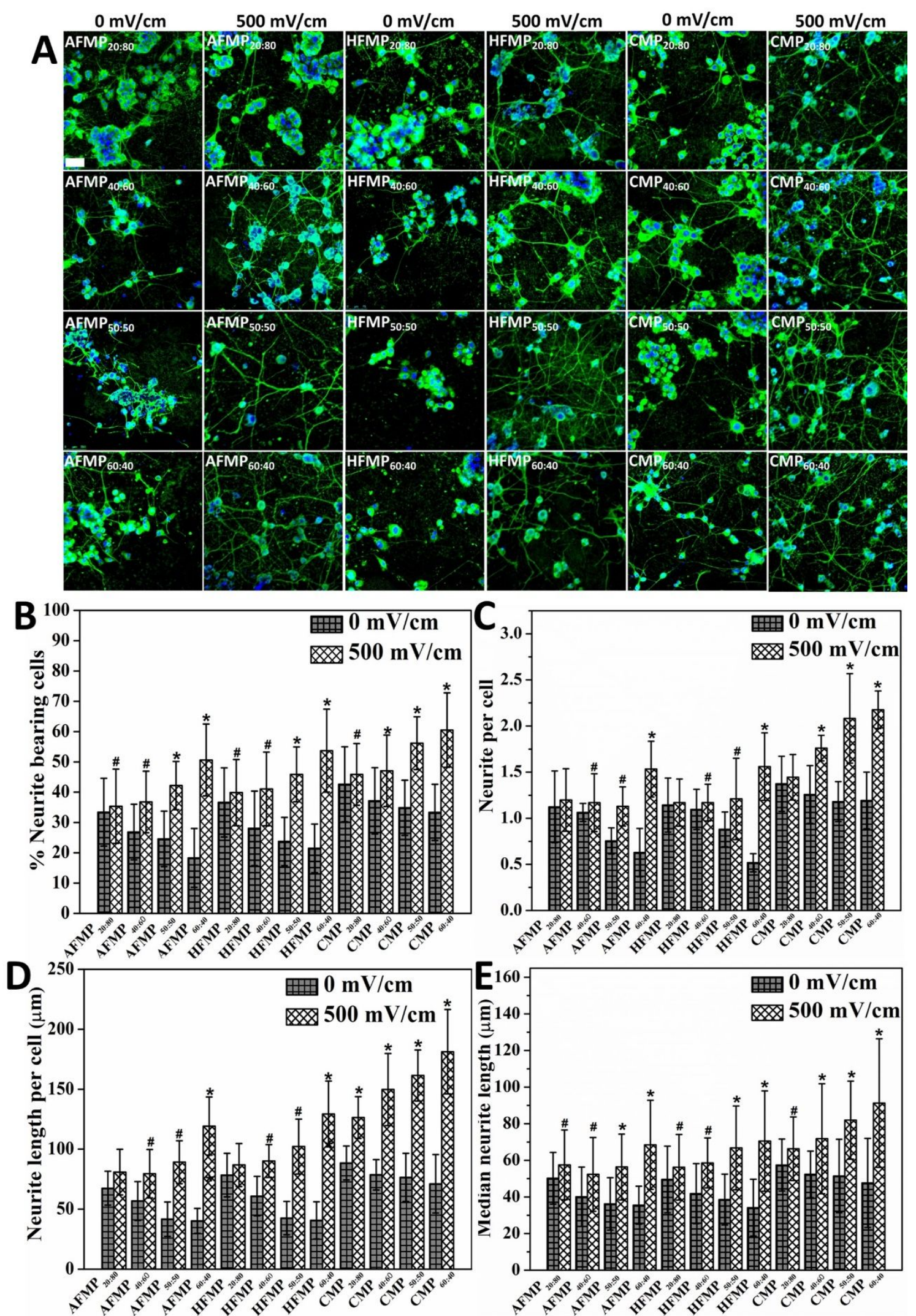

Figure 15. A. Beta (III) immunostaining of the electrically unstimulated and stimulated PC12 cells on the surface functionalized and collagen coated MEH-PPV:PCL mats for one week as indicated [Scale bar $=75 \mu \mathrm{m}$ ]. Quantitative analysis results showing (B) 
Percentage of neurite bearing cells, (C) Neurite per cell, (D) Neurite length per cell and (E) Median neurite length of differentiated PC12 cells on various conductive mats with ES and no ES. Data are Mean \pm S.D. ${ }^{*}$ and ${ }^{\#}$ indicate statistical significance at $p \leq 0.01$ and $\mathrm{p} \leq 0.05$.

The greater percent of neurite bearing cells and neurites per cell under ES indicated that the electrically stimulated PC12 cells showed increased neural differentiation as well as the increased neurite formation on various versions of scaffolds [Figure 15 (B\&C)]. Similarly, the electrically stimulated cells exhibited enhanced neurite length per cell and median neurite length suggesting accelerated neurite outgrowth [Figure $15(\mathbf{D} \& \mathbf{E})]$. The differences in these neuronal characteristics are statistically significant between the no ES and ES applied groups at $p \leq 0.01$ or $p \leq 0.05$ as indicated in Figure 15 (B-E). Interestingly, the neurite development and elongation of the electrically stimulated cells on the amine functionalized mats are equivalent or better as compared to the collagen coated mats without ES. In fact, the stimulated cells develop more neurite and show greater neurite extension on $\mathrm{AFMP}_{50: 50}, \mathrm{AFMP}_{60: 40}, \mathrm{HFMP}_{50: 50}$, and $\mathrm{HFMP}_{60: 40}$ as compared to the collagen coated mats without ES, which are significantly different at $\mathrm{p} \leq 0.01$. However, cells with ES on the collagen coated mats demonstrated significantly improved neurite development and extension as compared to the surface functionalized mats under the same condition, which is consistent with our previous report. ${ }^{15}$ Furthermore, there are no statistically significant differences in neurite development and extension on APTES and HDA functionalized electrospun mats at $\alpha=0.01$ or 0.05 $(p=0.12)$.
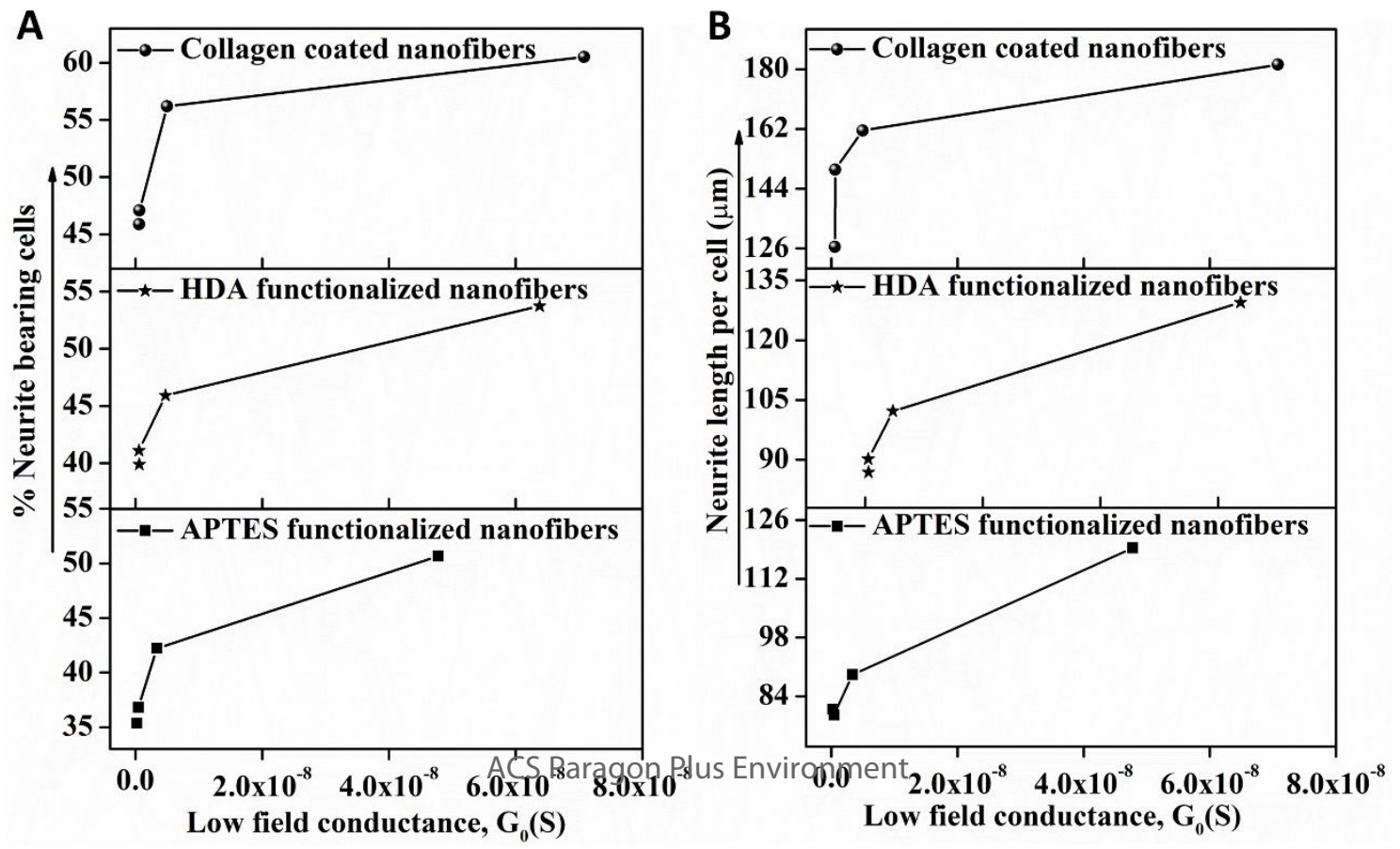
Figure 16. Effect of biomaterials' intrinsic conductivity on neurite development and outgrowth. Variations of (A) Neurite bearing cell count and (B) average neurite length on the functionalized and collagen coated MEH-PPV:PCL mats with respect to their intrinsic low field conductance $\left(\mathrm{G}_{\mathrm{o}}\right)$ values.

There is a distinction in neuronal characteristics of cells grown on different electrospun mats under no ES and ES condition depending on the MEH-PPV:PCL ratio. For instance, the electrospun mats with higher PCL content having larger nanofibers (lower electrical conductivity) showed greater neurite formation and elongation as compared to those on the mats with higher MEH-PPV content having smaller nanofibers (higher electrical conductivity) under no ES. This observation is consistent with the results discussed in the Sections 4.1, 4.2.1 and 4.3.1, that the combined effect of PCL content and the fiber diameter played the major role in dictating the 3T3 and PC12 cell activities. Notwithstanding, these neuronal characteristics were upregulated on smaller nanofibers as compared to the larger nanofibers under ES. The smaller nanofibers with more conductive MEH-PPV concentration aided better ES of PC12 cells within safe limit. Oneway ANOVA analysis showed that the neurite bearing cells, neurite per cell, neurite length per cell and median neurite length, under constant ES, on the electrospun mats having higher MEH-PPV content viz., $\mathrm{AFMP}_{50: 50}, \mathrm{HFMP}_{50: 50}, \mathrm{AFMP}_{60: 40}, \mathrm{HFMP}_{60: 40}$, $\mathrm{CMP}_{50: 50}$ and $\mathrm{CMP}_{60: 40}$ were considerably greater than those on the electrospun mats with relatively lower MEH-PPV content, viz., $\mathrm{AFMP}_{20: 80}, \mathrm{AFMP}_{40: 60}, \mathrm{HFMP}_{20: 80}, \mathrm{HFMP}_{40: 60}$, $\mathrm{CMP}_{20: 80}$, and $\mathrm{CMP}_{40: 60}(\mathrm{p} \leq 0.01)$. This observation reveals that intrinsic electrical conductivity plays a dominating role in the expression of the neuronal characteristics of the cells under ES. The results suggest an increasing trend of neurite development and extension under constant ES with increasing MEH-PPV concentration in the nanofibers. The real-time current signal recorded during ES experiment shown in Figure S11 indicates that there is systemic improvement in neurite development and extension with increase in current value $(<9 \mu \mathrm{A})$ through the conductive electrospun mats during ES in the order

of $\mathrm{CMP}_{60: 40}>\mathrm{HFMP}_{60: 40}>\mathrm{CMP}_{50: 50}>\mathrm{HFMP}_{50: 50}>\mathrm{AFMP}_{60: 40}>\mathrm{AFMP}_{50: 50}>\mathrm{CMP}_{60: 40}>\mathrm{CMP}_{20: 8}$ ${ }_{0}>\mathrm{HFMP}_{40: 60}>\mathrm{AFMP}_{40: 60}>\mathrm{HFMP}_{20: 80}>\mathrm{AFMP}_{20: 80}$. Zhang et al. reported that current lower than $10 \mu \mathrm{A}$ is suitable for accelerated neurite formation in PC12 cells beyond which it reduces. ${ }^{69}$ Notably, ES was also found to enhance the cell adhesion on the surface 
functionalized mats since there were more cells available for analysis as compared to the no ES condition [Table S3].

The electrospun mats with higher MEH-PPV content, particularly, $\mathrm{MP}_{50: 50}$ and $\mathrm{MP}_{60: 40}$ along with their functionalized counterparts have higher free charge carriers (lower critical voltage, $\left.V_{c}\right)$, higher value of low field conductance $\left(G_{0}\right)$ and lower sheet resistance $\left(\mathrm{R}_{\mathrm{s}}\right)$. As stated previously, MEH-PPV has high density of holes and traps, which enables the charge carrier to hop along the polymer chain easily under applied electric potential. With increase in MEH-PPV content in the nanofibers, density of holes and traps also increases. Consequently, the movement of free charge carriers becomes easier contributing towards higher conductance $\left(G_{o}\right)$ at lower electric potential as in the case of ES under $500 \mathrm{mV} / \mathrm{cm}$. The neurite development and outgrowth on the functionalized and collagen coated MEH-PPV:PCL mats were upregulated with increase in their intrinsic low field conductance $\left(G_{o}\right)$ values [Figure $16(\mathbf{A} \& \mathbf{B})$ ]. Thus, the intrinsic conductive properties of a biomaterial such as density of free charge carrier, density of holes-traps followed by low field conductance have a major role in determining the suitable ES voltage (within safe limit for cells) for accelerated neurite development.

MEH-PPV based electrically conductive electrospun mats allow for better charge-transfer between the cells and biomaterial during ES, leading to alteration in the steady state transmembrane potential of cells through membrane depolarization. ${ }^{70,71}$ The occurrence of this specific electrical event, termed as action potential, effects the ion influx through the membrane to condition the intracellular signal transduction pathways through second messengers such as cAMP and $\mathrm{Ca}^{2+}$, which in turn regulate enzyme phosphorylation and gene expression important for axonal growth. ${ }^{72,73} \mathrm{ES}$ mediated $\mathrm{Ca}^{2+}$ influx plays a crucial role in the release of neuromodulators and hormones, tubulin polymerization and microtubule formation and protein phosphorylation and thereby, contributes towards assembly and molecular organization of a growing nerve. According to Patel and Poo, 1982, ES mediated alteration in membrane potential may also cause electrophoretic distribution of cytoplasmic materials important for axonal growth. ${ }^{70}$ ES was also found to induce electrophoretic accumulation of surface molecules on scaffolds (e.g. serum proteins, NGF in media) that promote neurite adhesion and outgrowth. Although the exact mechanism of ES mediated accelerated nerve regeneration still not known, a series of studies reported upregulation of various growth factors and regeneration associated genes both in neurons and supporting cells responsible for nerve regeneration. ${ }^{74-76}$ Therefore, 
all the ES mediated processes discussed above likely to induce accelerated neurite formation outgrowth on the various MEH-PPV:PCL electrospun mats.

\section{Conclusions}

We have shown electrospinning of blended MEH-PPV and PCL to produce electrically conductive bead free nanofibers with variation in the volume ratio of the constituents, which are electrically conductive, porous, and mechanically strong as confirmed by SEM, IV characteristics, and tensile test. Next, their bioactivity was optimized by incorporating amine functionality through post-synthesis surface functionalization using APTES and HDA to regulate 3T3 fibroblasts activity and electrically stimulated neural differentiation of PC12 cell. We have demonstrated that ES dictates in controlling the PC12 cell behaviour including cell adhesion, neurite development and extension. Moreover, a study of voltage dependent conduction mechanism revealed that MEH-PPV:PCL nanofibers with higher free charge carriers and low field conductance are more suitable for electrically stimulated, enhanced neural cell function under low level electrical stimulation. The results further validate our hypothesis as the surface functionalized mats demonstrated similar or better neurite development under ES than on the collagen coated mats with no ES. Ultimately, the surface amination of the MEH-PPV:PCL nanofibers in combination with ES may be a versatile strategy as an alternative to conventional coating of biomaterials using expensive biomolecule for neural applications.

\section{Associated Content}

Supporting Information: Schematic illustration of electrospinning process; Methods of XRD analysis, XPS, IV measurement, hemolysis activity study, and image analysis; Determination of critical voltage $\left(\mathrm{V}_{\mathrm{c}}\right)$, SEM images of materials incubated for 45 days in physiological condition, FT-IR of constituents, XPS survey scan results, hemolysis results, cell density, live PC12 cell imaging, IV characteristics and Kaiser fit data of collagen coated mats, and electrical stimulation supporting information.

\section{Acknowledgements}

RB gratefully acknowledges Department of Science and Technology (DST) and Department of Biotechnology (DBT), Government of India, and British Council, UK for funding support. All authors thank Dr. Santanu Ray, School of Environment and Technology, University of Brighton, UK for the help in XPS measurement. Authors are 
thankful to Image and Analysis unit, University of Brighton for helping in SEM and confocal microscopy measurement.

\section{Conflicts of interest}

There are no conflicts of interest to declare.

\section{References}

(1) Bendorf, A.; Kelly, P. J.; Kerridge, I. H.; McCaughan, G. W.; Myerson, B.; Stewart, C.; Pussell, B. A. An International Comparison of the Effect of Policy Shifts to Organ Donation Following Cardiocirculatory Death (DCD) on Donation Rates after Brain Death (DBD) and Transplantation Rates. PLoS One 2013, 8 (5), 3-9. https://doi.org/10.1371/journal.pone.0062010.

(2) Schmidt, C. E.; Leach, J. B. Neural Tissue Engineering: Strategies for Repair and Regeneration. Annu. Rev. Biomed. Eng. 2003, 5 (1), 293-347. https://doi.org/10.1146/annurev.bioeng.5.011303.120731.

(3) Houschyar, K. S.; Momeni, A.; Pyles, M. N.; Cha, J. Y.; Maan, Z. N.; Duscher, D.; Jew, O. S.; Siemers, F.; Schoonhoven, J. van. The Role of Current Techniques and Concepts in Peripheral Nerve Repair. Plast. Surg. Int. 2016, 2016, 1-8. https://doi.org/10.1155/2016/4175293.

(4) Vijayavenkataraman, S. Nerve Guide Conduits for Peripheral Nerve Injury Repair: A Review on Design, Materials and Fabrication Methods. Acta Biomater. 2020, 106 (xxxx), 54-69. https://doi.org/10.1016/j.actbio.2020.02.003.

(5) Katiyar, K. S.; Das, S.; Burrell, J. C.; Kacy Cullen, D. Scaffolds for Bridging Sciatic Nerve Gaps. In Handbook of Tissue Engineering Scaffolds: Volume Two; Mozafari, M., Sefat, F., Atala, A., Eds.; Elsevier Ltd: Cambridge (UK), 2019; pp 67-93. https://doi.org/10.1016/B978-0-08-102561-1.00003-8.

(6) Ruijs, A. C. J.; Jaquet, J. B.; Kalmijn, S.; Giele, H.; Hovius, S. E. R. Median and Ulnar Nerve Injuries: A Meta-Analysis of Predictors of Motor and Sensory Recovery after Modern Microsurgical Nerve Repair. Plast. Reconstr. Surg. 2005, 116 (2), 484-494. https://doi.org/10.1097/01.prs.0000172896.86594.07.

(7) Jia, X.; Romero-Ortega, M. I.; Teng, Y. D. Peripheral Nerve Regeneration: Mechanism, Cell Biology, and Therapies. Biomed Res. Int. 2014, 2014, 145304. https://doi.org/10.1155/2014/145304.

(8) Singh, A. K. Transcranial Doppler Flow Patterns in Brain Death : " Storm before 
the Calm " Carbon Monoxide Toxicity : A Reversible Damage to Brain. 2017, 65 (3), 671-673. https://doi.org/10.4103/neuroindia.NI.

(9) Samba, R.; Herrmann, T.; Zeck, G. PEDOT - CNT Coated Electrodes Stimulate Retinal Neurons at Low Voltage Amplitudes and Low Charge Densities. J. Neural Eng. 2015, 12 (1), 016014. https://doi.org/10.1088/17412560/12/1/016014.

(10) Yan, L.; Zhao, B.; Liu, X.; Li, X.; Zeng, C.; Shi, H.; Xu, X.; Lin, T.; Dai, L.; Liu, Y. Aligned Nanofibers from Polypyrrole/Graphene as Electrodes for Regeneration of Optic Nerve via Electrical Stimulation. ACS Appl. Mater. Interfaces 2016, 8 (11), 6834-6840. https://doi.org/10.1021/acsami.5b12843.

(11) Kotwal, A.; Schmidt, C. E. Electrical Stimulation Alters Protein Adsorption and Nerve Cell Interactions with Electrically Conducting Biomaterials. Biomaterials 2001, 22 (10), 1055-1064. https://doi.org/10.1016/S0142-9612(00)00344-6.

(12) Balint, R.; Cassidy, N. J.; Cartmell, S. H. Conductive Polymers: Towards a Smart Biomaterial for Tissue Engineering. Acta Biomater. 2014, 10 (6), 2341-2353. https://doi.org/10.1016/j.actbio.2014.02.015.

(13) Kwon, J. T.; Eom, S. H.; Moon, B. S.; Shin, J. K.; Kim, K. S.; Lee, S. H.; Lee, Y. S. Studies on Printing Inks Containing Poly[2-Methoxy-5-(2-Ethylhexyl-Oxyl)-1, 4-Phenylenevinylene] as an Emissive Material for the Fabrication of Polymer Light-Emitting Diodes by Inkjet Printing. Bull. Korean Chem. Soc. 2012, 33 (2), 464-468. https://doi.org/10.5012/bkcs.2012.33.2.464.

(14) Matharu, Z.; Arya, S. K.; Singh, S. P.; Gupta, V.; Malhotra, B. D. Analytica Chimica Acta Langmuir - Blodgett Film Based on MEH-PPV for Cholesterol Biosensor. 2009, 634, 243-249. https://doi.org/10.1016/j.aca.2008.12.023.

(15) Borah, R.; Ingavle, G. C.; Sandeman, S. R.; Kumar, A.; Mikhalovsky, S. Electrically Conductive MEH-PPV:PCL Electrospun Nanofibres for Electrical Stimulation of Rat PC12 Pheochromocytoma Cells. Biomater. Sci. 2018, 6 (9), 2342-2359. https://doi.org/10.1039/c8bm00559a.

(16) Hersel, U.; Dahmen, C.; Kessler, H. RGD Modified Polymers: Biomaterials for Stimulated Cell Adhesion and Beyond. Biomaterials 2003, 24 (24), 4385-4415. https://doi.org/10.1016/S0142-9612(03)00343-0.

(17) Nickels, J. D.; Schmidt, C. E. Surface Modification of the Conducting Polymer, Polypyrrole, via Affinity Peptide. J. Biomed. Mater. Res. - Part A 2013, 101 A (5), 1464-1471. https://doi.org/10.1002/jbm.a.34435. 
(18) Lee, J. H.; Lee, J. W.; Khang, G.; Lee, H. B. Interaction of Cells on Chargeable Functional Group Gradient Surfaces. Biomaterials 1997, 18 (4), 351-358. https://doi.org/10.1016/S0142-9612(96)00128-7.

(19) Arnold, K.; Davies, B.; Giles, R. L.; Grosjean, C.; Smith, G. E.; Whiting, A. To Catalyze or Not to Catalyze? Insight into Direct Amide Bond Formation from Amines and Carboxylic Acids under Thermal and Catalyzed Conditions. Adv. Synth. Catal. 2006, 348 (7-8), 813-820. https://doi.org/10.1002/adsc.200606018.

(20) Mansur, H. S.; Oréfice, R. L.; Vasconcelos, W. L.; Lobato, Z. P.; Machado, L. J. C. Biomaterial with Chemically Engineered Surface for Protein Immobilization. J. Mater. Sci. Mater. Med. 2005, 16 (4), 333-340. https://doi.org/10.1007/s10856-005-0632-y.

(21) Zhu, M.; Lerum, M. Z.; Chen, W. How to Prepare Reproducible, Homogeneous, and Hydrolytically Stable Aminosilane-Derived Layers on Silica. Langmuir 2012, 28 (1), 416-423. https://doi.org/10.1021/la203638g.

(22) Fan, D.; De Rosa, E.; Murphy, M. B.; Peng, Y.; Smid, C. A.; Chiappini, C.; Liu, X.; Simmons, P.; Weiner, B. K.; Ferrari, M.; Tasciotti, E. Mesoporous SiliconPLGA Composite Microspheres for the Double Controlled Release of Biomolecules for Orthopedic Tissue Engineering. Adv. Funct. Mater. 2012, 22 (2), 282-293. https://doi.org/10.1002/adfm.201100403.

(23) Liang, Y.; Huang, J.; Zang, P.; Kim, J.; Hu, W. Molecular Layer Deposition of APTES on Silicon Nanowire Biosensors: Surface Characterization, Stability and PH Response. Appl. Surf. Sci. 2014, 322, 202-208. https://doi.org/10.1016/j.apsusc.2014.10.097.

(24) Li, W. A.; Lu, B. Y.; Gu, L.; Choi, Y.; Kim, J.; Mooney, D. J. The Effect of Surface Modification of Mesoporous Silica Micro-Rod Scaffold on Immune Cell Activation and Infiltration. Biomaterials 2016, 83, 249-256. https://doi.org/10.1016/j.biomaterials.2016.01.026.

(25) Santiago, L. Y.; Nowak, R. W.; Rubin, J. P.; Marra, K. G. Peptide-Surface Modification of Poly(Caprolactone) with Laminin-Derived Sequences for Adipose-Derived Stem Cell Applications. Biomaterials 2006, 27 (15), 2962 2969. https://doi.org/10.1016/j.biomaterials.2006.01.011.

(26) Borah, R.; Ingavle, G. C.; Sandeman, S. R.; Kumar, A.; Mikhalovsky, S. V. Amine-Functionalized Electrically Conductive Core-Sheath MEH-PPV:PCL Electrospun Nanofibers for Enhanced Cell-Biomaterial Interactions. ACS 
Biomater. Sci. Eng. 2018, 4 (9), 3327-3346.

https://doi.org/10.1021/acsbiomaterials.8b00624.

(27) Promega. CellTiter 96 ® AQueous One Solution Cell Proliferation Assay. Www.Promega.Com/Protocols/2012, 2014-12-15.

(28) Cheng, H.; Yue, K.; Kazemzadeh-Narbat, M.; Liu, Y.; Khalilpour, A.; Li, B.; Zhang, Y. S.; Annabi, N.; Khademhosseini, A. Mussel-Inspired Multifunctional Hydrogel Coating for Prevention of Infections and Enhanced Osteogenesis. ACS Appl. Mater. Interfaces 2017, 9 (13), 11428-11439.

(29) Yang, H.; Zhu, G.; Huang, Y.; Shi, X.; Wang, Y. The Stimulation of the Differentiation of Pheochromocytoma (PC12-L) Cells into Neuron-like Cells by Electrically Conductive Nanofibre Mesh. Appl. Mater. Today 2016, 5, 215-222.

(30) Zhong, W.; Li, F.; Chen, L.; Chen, Y.; Wei, Y. A Novel Approach to Electrospinning of Pristine and Aligned MEH-PPV Using Binary Solvents. $J$. Mater. Chem. 2012, 22 (12), 5523-5530. https://doi.org/10.1039/c2jm15970h.

(31) Zhao, Q.; Xin, Y.; Huang, Z.; Liu, S.; Yang, C.; Li, Y. Using Poly [2-Methoxy-5(2'-Ethyl-Hexyloxy)-1, 4-Phenylene Vinylene] as Shell to Fabricate the Highly Fluorescent Nanofibers by Coaxial Electrospinning. Polymer (Guildf). 2007, 48 (15), 4311-4315.

(32) Borjigin, M.; Eskridge, C.; Niamat, R.; Strouse, B.; Bialk, P.; Kmiec, E. B. Electrospun Fiber Membranes Enable Proliferation of Genetically Modified Cells. Int. J. Nanomedicine 2013, 8, 855.

(33) Masse, M. A.; Schlenoff, J. B.; Karasz, F. E.; Thomas, E. L. Crystalline Phases of Electrically Conductive Poly (P-phenylene Vinylene). J. Polym. Sci. Part B Polym. Phys. 1989, 27 (10), 2045-2059.

(34) Okuzaki, H.; Yan, H. Uniaxially Aligned Poly (p-Phenylene Vinylene) and Carbon Nanofiber Yarns through Electrospinning of a Precursor. In Ferroelectrics; Coondoo, I., Ed.; IntechOpen, 2010; pp 139-154.

(35) Abbassi, F.; Mbarek, M.; Kreher, D.; Alimi, K. Synthesis and Characterization of a Copolymer Involving PVK and MEH-PPV for Organic Electronic Devices. $J$. Phys. Chem. Solids 2017, 103, 142-146.

(36) Hazarika, J.; Kumar, A. Scalable and Low Cost Synthesis of Highly Conducting Polypyrrole Nanofibers Using Oil-Water Interfacial Polymerization under Constant Stirring. J. Phys. Chem. B 2017, 121 (28), 6926-6933.

(37) Lampert, M. A.; Schilling, R. B. Current Injection in Solids: The Regional 
Approximation Method. In Semiconductors and semimetals; Elsevier, 1970; Vol. 6 , pp 1-96.

(38) Kao Kwan, C.; Hwang, W. Electrical Transport in Solids: With Particular Reference to Organic Semiconductors; Pergamon Press, 1981.

(39) Kaiser, A. B.; Park, Y. W. Current-Voltage Characteristics of Conducting Polymers and Carbon Nanotubes. Synth. Met. 2005, 152 (1-3), 181-184.

(40) Milleret, V.; Simona, B.; Neuenschwander, P.; Hall, H. Tuning Electrospinning Parameters for Production of 3D-Fiber-Fleeces with Increased Porosity for Soft Tissue Engineering Applications. Eur Cell Mater 2011, 21 (1473-2262), 286303.

(41) Wang, Z.; Cui, Y.; Wang, J.; Yang, X.; Wu, Y.; Wang, K.; Gao, X.; Li, D.; Li, Y.; Zheng, X.-L. The Effect of Thick Fibers and Large Pores of Electrospun Poly ( $\varepsilon$-Caprolactone) Vascular Grafts on Macrophage Polarization and Arterial Regeneration. Biomaterials 2014, 35 (22), 5700-5710.

(42) Xu, Z.; Liu, Q.; Finch, J. A. Silanation and Stability of 3-Aminopropyl Triethoxy Silane on Nanosized Superparamagnetic Particles: I. Direct Silanation. Appl. Surf. Sci. 1997, 120 (3-4), 269-278.

(43) Choi, K. H.; Kim, H. B.; Ali, K.; Sajid, M.; Siddiqui, G. U.; Chang, D. E.; Kim, H. C.; Ko, J. B.; Dang, H. W.; Doh, Y. H. Hybrid Surface Acoustic WaveElectrohydrodynamic Atomization (SAW-EHDA) for the Development of Functional Thin Films. Sci. Rep. 2015, 5, 15178.

(44) Roque, A. P.; Mercante, L. A.; Scagion, V. P.; Oliveira, J. E.; Mattoso, L. H. C.; De Boni, L.; Mendonca, C. R.; Correa, D. S. Fluorescent PMMA/MEH-PPV Electrospun Nanofibers: Investigation of Morphology, Solvent, and Surfactant Effect. J. Polym. Sci. Part B Polym. Phys. 2014, 52 (21), 1388-1394.

(45) Juhari, N.; Majid, W. H. A.; Ibrahim, Z. A. Structural and Optical Studies of MEH-PPV Using Two Different Solvents Prepared by Spin Coating Technique. Solid State Sci. Technol. 2007, 15 (1), 141-146.

(46) Elzein, T.; Nasser-Eddine, M.; Delaite, C.; Bistac, S.; Dumas, P. FTIR Study of Polycaprolactone Chain Organization at Interfaces. J. Colloid Interface Sci. 2004, 273 (2), 381-387.

(47) Benkaddour, A.; Jradi, K.; Robert, S.; Daneault, C. Grafting of Polycaprolactone on Oxidized Nanocelluloses by Click Chemistry. Nanomaterials 2013, 3 (1), $141-157$. 
(48) Tang, Z. G.; Black, R. A.; Curran, J. M.; Hunt, J. A.; Rhodes, N. P.; Williams, D. F. Surface Properties and Biocompatibility of Solvent-Cast Poly [e-Caprolactone] Films. Biomaterials 2004, 25 (19), 4741-4748.

(49) Pavia, D. L.; Lampman, G. M.; Kriz, G. S.; Vyvyan, J. A. Introduction to Spectroscopy; Cengage Learning, 2008.

(50) Majoul, N.; Aouida, S.; Bessaïs, B. Progress of Porous Silicon APTESFunctionalization by FTIR Investigations. Appl. Surf. Sci. 2015, 331, 388-391.

(51) Atreya, M.; Li, S.; Kang, E. T.; Neoh, K. G.; Ma, Z. H.; Tan, K. L.; Huang, W. Stability Studies of Poly (2-Methoxy-5-(2'-Ethyl Hexyloxy)-p-(Phenylene Vinylene)[MEH-PPV]. Polym. Degrad. Stab. 1999, 65 (2), 287-296.

(52) Louette, P.; Bodino, F.; Pireaux, J.-J. Poly (Caprolactone)(PCL) XPS Reference Core Level and Energy Loss Spectra. Surf. Sci. Spectra 2005, 12 (1), 27-31.

(53) Lee, J.-W.; Serna, F.; Nickels, J.; Schmidt, C. E. Carboxylic Acid-Functionalized Conductive Polypyrrole as a Bioactive Platform for Cell Adhesion.

Biomacromolecules 2006, 7 (6), 1692-1695.

(54) López-Pérez, P. M.; Marques, A. P.; da Silva, R. M. P.; Pashkuleva, I.; Reis, R. L. Effect of Chitosan Membrane Surface Modification via Plasma Induced Polymerization on the Adhesion of Osteoblast-like Cells. J. Mater. Chem. 2007, 17 (38), 4064-4071.

(55) Yuan, S.; Xiong, G.; Roguin, A.; Teoh, S. H.; Choong, C. Amelioration of Blood Compatibility and Endothelialization of Polycaprolactone Substrates by SurfaceInitiated Atom Transfer Radical Polymerization. Adv. Biomater. Sci. Biomed. Appl. Pignatello, R., Ed 2013, 177-205.

(56) Smallwood, I. Handbook of Organic Solvent Properties; ButterworthHeinemann, 2012.

(57) Vashist, S. K.; Lam, E.; Hrapovic, S.; Male, K. B.; Luong, J. H. T. Immobilization of Antibodies and Enzymes on 3-AminopropyltriethoxysilaneFunctionalized Bioanalytical Platforms for Biosensors and Diagnostics. Chem. Rev. 2014, 114 (21), 11083-11130.

(58) Asenath Smith, E.; Chen, W. How to Prevent the Loss of Surface Functionality Derived from Aminosilanes. Langmuir 2008, 24 (21), 12405-12409.

(59) Howarter, J. A.; Youngblood, J. P. Surface Modification of Polymers with 3Aminopropyltriethoxysilane as a General Pretreatment for Controlled Wettability. Macromolecules 2007, 40 (4), 1128-1132. 
(60) Bruice, P. Y. Organic Chemistry. International Edition. Pearson Education, Upper Saddle River, NJ, USA, 2004.

(61) Bae, S. H.; Che, J.-H.; Seo, J.-M.; Jeong, J.; Kim, E. T.; Lee, S. W.; Koo, K.; Suaning, G. J.; Lovell, N. H.; Kim, S. J. In Vitro Biocompatibility of Various Polymer-Based Microelectrode Arrays for Retinal Prosthesis. Invest.

Ophthalmol. Vis. Sci. 2012, 53 (6), 2653-2657.

(62) Bashur, C. A.; Dahlgren, L. A.; Goldstein, A. S. Effect of Fiber Diameter and Orientation on Fibroblast Morphology and Proliferation on Electrospun Poly (D, L-Lactic-Co-Glycolic Acid) Meshes. Biomaterials 2006, 27 (33), 5681-5688.

(63) Badami, A. S.; Kreke, M. R.; Thompson, M. S.; Riffle, J. S.; Goldstein, A. S. Effect of Fiber Diameter on Spreading, Proliferation, and Differentiation of Osteoblastic Cells on Electrospun Poly (Lactic Acid) Substrates. Biomaterials 2006, 27 (4), 596-606.

(64) Pires, F.; Ferreira, Q.; Rodrigues, C. A. V; Morgado, J.; Ferreira, F. C. Neural Stem Cell Differentiation by Electrical Stimulation Using a Cross-Linked PEDOT Substrate: Expanding the Use of Biocompatible Conjugated Conductive Polymers for Neural Tissue Engineering. Biochim. Biophys. Acta (BBA)-General Subj. 2015, 1850 (6), 1158-1168.

(65) Gladwin, K. M.; Whitby, R. L. D.; Mikhalovsky, S. V; Tomlins, P.; Adu, J. In Vitro Biocompatibility of Multiwalled Carbon Nanotubes with Sensory Neurons. Adv. Healthc. Mater. 2013, 2 (5), 728-735.

(66) Lee, J. Y.; Bashur, C. A.; Goldstein, A. S.; Schmidt, C. E. Polypyrrole-Coated Electrospun PLGA Nanofibers for Neural Tissue Applications. Biomaterials 2009, 30 (26), 4325-4335.

(67) Lee, J. H.; Lee, J. W.; Khang, G.; Lee, H. B. Interaction of Cells on Chargeable Functional Group Gradient Surfaces. Biomaterials 1997, 18 (4), 351-358.

(68) Rajnicek, A. M.; Robinson, K. R.; McCaig, C. D. The Direction of Neurite Growth in a Weak DC Electric Field Depends on the Substratum: Contributions of Adhesivity and Net Surface Charge. Dev. Biol. 1998, 203 (2), 412-423.

(69) Lee, J. Y.; Bashur, C. A.; Gomez, N.; Goldstein, A. S.; Schmidt, C. E. Enhanced Polarization of Embryonic Hippocampal Neurons on Micron Scale Electrospun Fibers. J. Biomed. Mater. Res. Part A An Off. J. Soc. Biomater. Japanese Soc. Biomater. Aust. Soc. Biomater. Korean Soc. Biomater. 2010, 92 (4), 1398-1406. (70) Patel, N.; Poo, M.-M. Orientation of Neurite Growth by Extracellular Electric 
Fields. J. Neurosci. 1982, 2 (4), 483-496.

(71) Mattioli-Belmonte, M.; Giavaresi, G.; Biagini, G.; Virgili, L.; Giacomini, M.; Fini, M.; Giantomassi, F.; Natali, D.; Torricelli, P.; Giardino, R. Tailoring Biomaterial Compatibility: In Vivo Tissue Response versus in Vitro Cell Behavior. Int. J. Artif. Organs 2003, 26 (12), 1077-1085.

(72) Kamber, D.; Erez, H.; Spira, M. E. Local Calcium-Dependent Mechanisms Determine Whether a Cut Axonal End Assembles a Retarded Endbulb or Competent Growth Cone. Exp. Neurol. 2009, 219 (1), 112-125.

(73) Meng, S.; Rouabhia, M.; Zhang, Z.; De D, D. F.; Laval, U. Electrical Stimulation in Tissue Regeneration. Appl. Biomed. Eng. 2011, 37-62.

(74) Al-Majed, A. A.; Tam, S. L.; Gordon, T. Electrical Stimulation Accelerates and Enhances Expression of Regeneration-Associated Genes in Regenerating Rat Femoral Motoneurons. Cell. Mol. Neurobiol. 2004, 24 (3), 379-402.

(75) Al-Majed, A. A.; Brushart, T. M.; Gordon, T. Electrical Stimulation Accelerates and Increases Expression of BDNF and TrkB MRNA in Regenerating Rat Femoral Motoneurons. Eur. J. Neurosci. 2000, 12 (12), 4381-4390.

Qian, Y.; Cheng, Y.; Cai, J.; Zhao, X.; Ouyang, Y.; Yuan, W.-E.; Fan, C. Advances in Electrical and Magnetic Stimulation on Nerve Regeneration. Regen. Med. 2019, 14 (10), 969-979.

\section{Table of Contents Graphic and Synopsis}

Blend of MEH-PPV with PCL was electrospun to produce uniform, porous, electrically conductive, mechanically strong and physiologically stable nanofibrous scaffold. The nanofibrous scaffolds were surface functionalized using APTES and HDA to bestow bioactivity for enhanced cell adhesion, spreading and proliferation, including modulation of neural differentiation of rat PC12 cell lines. When coupled with externally applied electrical stimulus through the electroconductive scaffolds, they showed comparable or faster neurite formation and elongation than the collagen coated scaffolds with no ES condition. MEH-PPV:PCL nanofibers with better low field conductance owing to high density of holes and traps along with high density free charge carriers, which makes it a suitable electroconductive scaffold for low level neuronal stimulation. The study 
demonstrated surface amination in combination with ES could provide an improved approach for faster nerve regeneration using an electrically conductive MEH-PPV based neural scaffold.

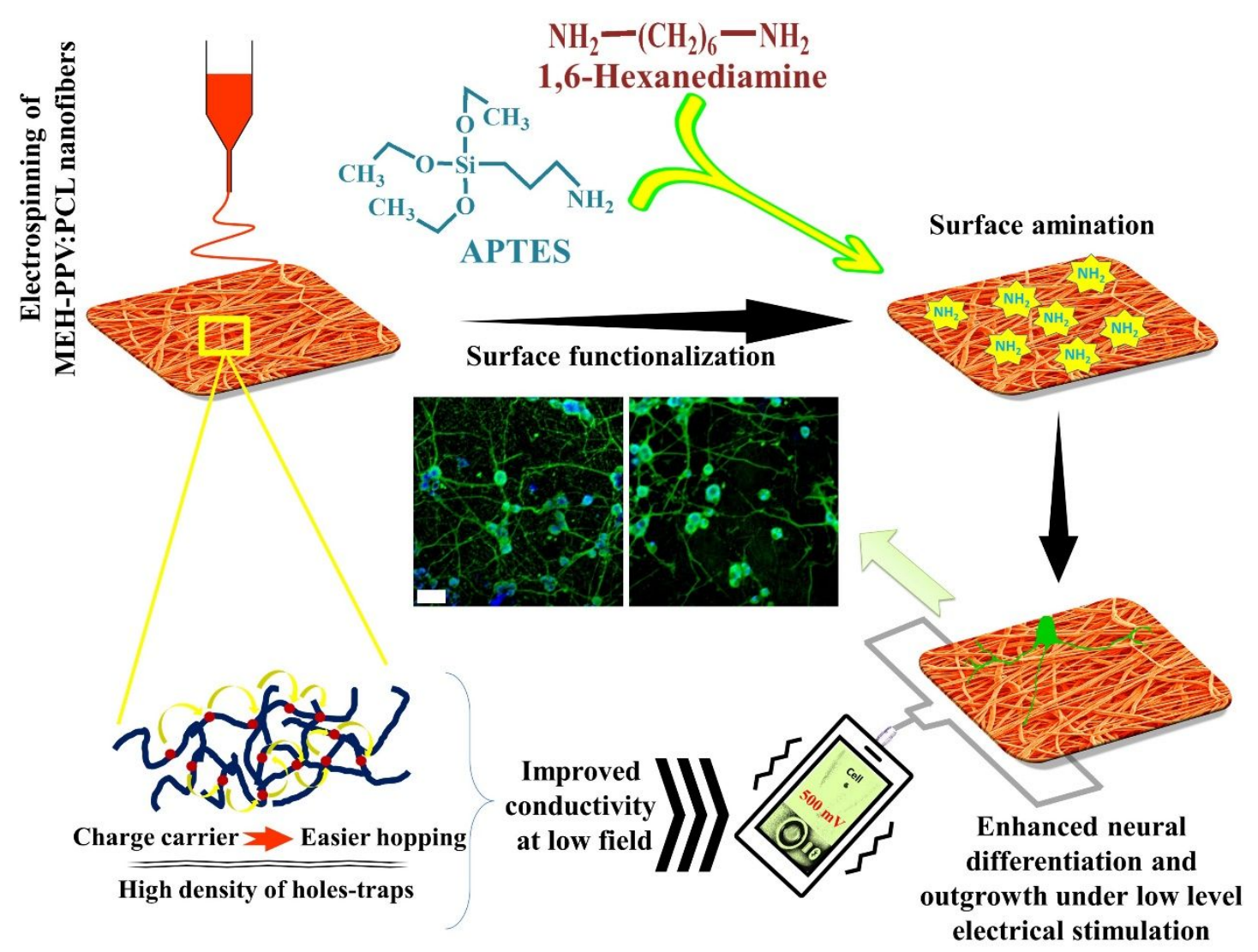

